\title{
Metastability and seeding effects in the mechanochemical hybrid lead(II) iodide formation
}

\author{
Manuel Wilke ${ }^{a}$, Dariusz Jakub Gawryluk ${ }^{b}$, and Nicola Casati*a \\ ${ }^{a}$ Laboratory for Synchrotron Radiation - Condensed Matter, Paul Scherrer Institute, 5232 Villigen \\ PSI, Switzerland, nicola.casati@psi.ch, +41-56-310-5346 \\ bLaboratory for Multiscale materials eXperiments, Paul Scherrer Institute, 5232 Villigen PSI, \\ Switzerland
}

\begin{abstract}
We present the mechanism for the mechanochemical synthesis of $\left(\mathrm{C}\left(\mathrm{NH}_{2}\right)_{3}\right)_{3} \mathrm{Pbl}_{5} 3$ and $\left(\mathrm{C}\left(\mathrm{NH}_{2}\right)_{3}\right)_{4} \mathrm{Pbl}_{6} 4$ and their conversion into each other. We investigated the syntheses of $\mathbf{3}$ at different frequencies and energies using in situ powder $\mathrm{X}$-ray diffraction. By splitting the reaction into single parts we could prove that the formation of $\mathbf{3}$ is simply dependent on the energy and mixing speed. The nucleation of $\mathbf{4}$ instead is slightly negative dependent on the energy but dependent on the mixing speed, while its growth is mostly independent of any influence. We were able to influence the reaction pathways by seeding the mixture with a small amount of powdery 4 . The formation of $\mathbf{4}$ is very likely an auto-catalytic process. $\mathbf{3}$ instead is metastable. It can be stabilized by energy, which beside mechanochemistry can also be achieved by temperature. The results showcases the complex nature of mechanochemical reactions.
\end{abstract}

\section{Introduction}

Mechanochemistry is known and investigated for decades ${ }^{1,2}$ but especially in the last years it has become one of the most promising new methods for solid state synthesis. The short reaction times, the small amounts of solvents used and the little production of waste makes it part of green chemistry. At the same time a wide range of reactions, processes and products can be achieved. The handling itself is easy; mechanochemical reactions are done in simple ball mills, planetary mills, extruder or even by hand using a mortar. ${ }^{3-7}$ On the other hand, it is still difficult to predict the outcome of new and more complex reactions as well as to upscale mechanochemical syntheses, based on the lack of knowledge of the underlying reaction mechanisms. Several setups were developed to investigate mechanochemical reactions in situ, using powder X-ray diffraction, Raman spectroscopy, temperature measuring devices, and combinations of these. ${ }^{8-14}$ Based on the gained results, some cornerstones could be found. Lots of mechanochemical reactions have a tendency to form crystalline intermediates and to undergo solid state phase transitions ending up in the stoichiometric product. ${ }^{15-19}$ Also amorphization could be observed. ${ }^{18,20-22}$ Recent in situ temperature studies on the formation of cocrystals, C$\mathrm{C}$ bonds and metal-organic frameworks could show that on the surface of vibration ball mill jars the measured increase of the temperature is small but nevertheless can be connected to the reaction pathway. ${ }^{11,12,14}$ Longer known is the methodology of liquid-assisted grinding (LAG). The addition of a small amount of liquid can initiate a reaction, dramatically speed it up or influence the reaction pathway and the obtained product. ${ }^{18,23-25}$ One possible initiation for mechanochemical reactivity is the mechanical activation of the reactants by forming defects within the solids. ${ }^{4,26}$ For a long time, only the frequency of the mill, the ball mass and the ball mass to powder ratio were taken into consideration for the energy input leading to the activation. Recently, it could be shown that also the ball surface area and material play an important role. ${ }^{27,28}$ First attempts were made to theoretically describe and understand the kinetics of mechanochemical reactions. ${ }^{29-33}$ Nevertheless, no general 


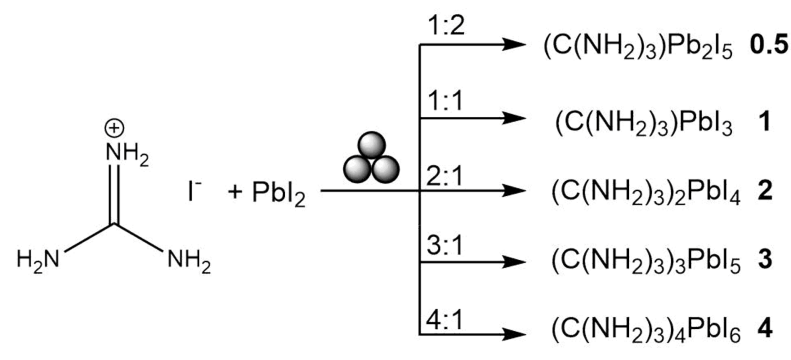

Figure 1: Syntheses of the different guanidinium lead(II) iodides.

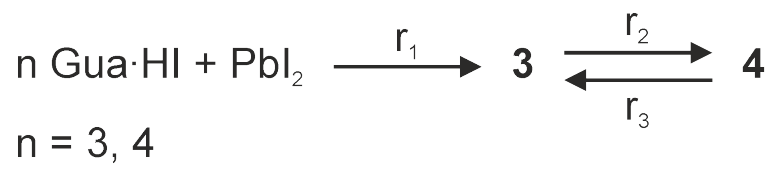

Figure 2: Formation scheme for $\mathbf{3}$ and $\mathbf{4}$ and their correlation. The endproduct is dictated by the given stoichiometry $\mathrm{n}$.

principles and concepts could be formulated so far and more and detailed in situ studies of mechanochemical reactions are needed.

During the last years, mechanochemistry was increasingly used for the production of metal halides and perovskites. ${ }^{34-37}$ The synthesized perovskites could be used for the construction of thin films and their photovoltaic properties were proven. ${ }^{38,39}$

Recently, we presented the mechanochemical synthesis of hybrid organic-inorganic materials of different dimensionality, constructed by guanidinium- (HGua), lead(II)- and iodide-ions, with the formula $\left(\mathrm{C}\left(\mathrm{NH}_{2}\right)_{3}\right)_{n} \mathrm{Pbl}_{2+n}$ $\left(\mathrm{n}=1,2,3\right.$, and 4) (Figure 1). ${ }^{40}$ The respective structures are shown in Figure 3a-d. In brief, the biggest differences are in the connection and dimensionality of the inorganic moiety, it goes from edge-sharing $\mathrm{Pbl}_{6}$ octahedra forming 1D double-chains (1), to a 2D perovskite structure (2), to a 1D single chain structure arranged by corner sharing $\mathrm{Pbl}_{6}$-octahedra (3) and finally to isolated $\mathrm{Pbl}_{6}$-octahedra (4). The guanidinium ions are always placed between the inorganic parts and the N-I-hydrogen bonds are getting shorter from 1-4. All four syntheses were investigated in situ by powder X-ray diffraction (PXRD). The reaction pathways revealed to be very complex, since the four guanidinium lead(II) iodides convert easily into each other during the milling process and one starting material forms an unexpected high temperature phase. The compounds 1-4 show very different behaviors in nucleation, growth and intermediate formation, which we linked to the structure of the inorganic motif and the presence of hydrogen bonds. The most unusual behavior was shown by compound $\mathbf{4}$ in relation to compound 3 . The nucleation of 4 is very slow but its growth afterward is the fastest. In the synthesis of $\mathbf{3}$ the formation of the final product is already ongoing and almost complete, when 4 finally nucleates as intermediate and stops the production of 3 .

To elucidate the mechanisms behind the formation under mechanochemical conditions, more and specialized in situ PXRD investigations were performed. We focused on the synthesis of $\mathbf{3}$ and $\mathbf{4}$, which are correlated (Figure 2). In particular we conducted the syntheses of $\mathbf{3}$ at different frequencies and energies, probed the single parts $\left(r_{1}, r_{2}\right.$, and $\left.r_{3}\right)$ of the reaction and investigated the influence of seeding by adding small amounts of the different polycrystalline compounds to the reaction mixture. The behavior of the system by applying temperature and its stability over a longer time period were also considered. Based on the gained results we present here a possible mechanism for the formation of $\mathbf{3}$ and $\mathbf{4}$ and their interconversion.

Novel structures of $\left(\mathrm{C}\left(\mathrm{NH}_{2}\right)_{3}\right)_{4} \mathrm{Pbl}_{6}$ at $370 \mathrm{~K}(4-\mathrm{II}),\left(\mathrm{C}\left(\mathrm{NH}_{2}\right)_{3}\right) \mathrm{Pb}_{2} \mathrm{I}_{5}$ at room temperature $(\mathbf{0 . 5})$ and at $490 \mathrm{~K}(\mathbf{0 . 5}-\mathrm{II})$ are also reported. 

a) $\left(\mathrm{C}\left(\mathrm{NH}_{2}\right)_{3}\right) \mathrm{Pbl}_{3} 1(298 \mathrm{~K})$
b) $\left(\mathrm{C}\left(\mathrm{NH}_{2}\right)_{3}\right)_{2} \mathrm{Pbl}_{4} 2(298 \mathrm{~K})$
c) $\left(\mathrm{C}\left(\mathrm{NH}_{2}\right)_{3}\right)_{3} \mathrm{Pbl}_{5} 3(298 \mathrm{~K})$
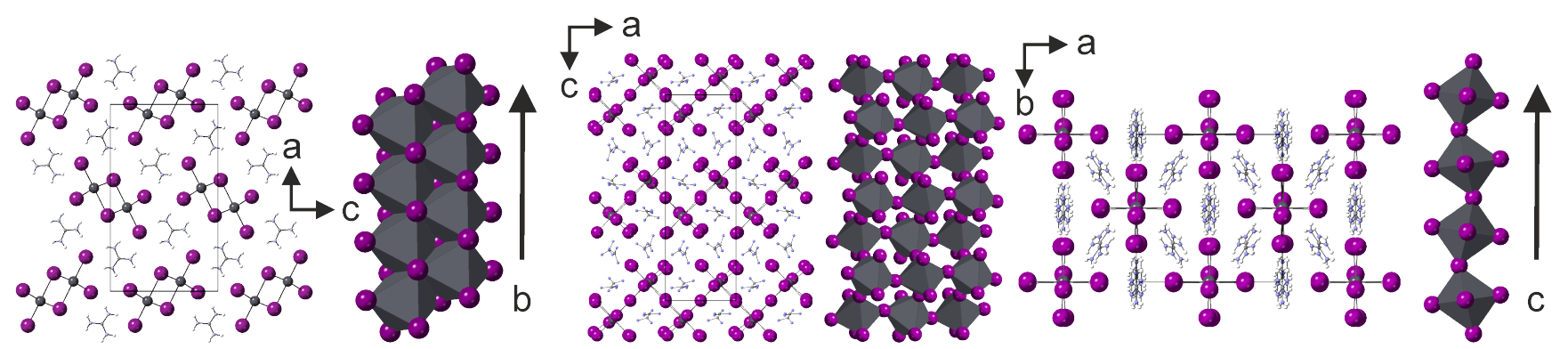

d) $\left(\mathrm{C}\left(\mathrm{NH}_{2}\right)_{3}\right)_{4} \mathrm{Pbl}_{6} 4(298 \mathrm{~K})$

e) $\left(\mathrm{C}\left(\mathrm{NH}_{2}\right)_{3}\right)_{4} \mathrm{Pbl}_{6} 4-\mathrm{II}(370 \mathrm{~K})$
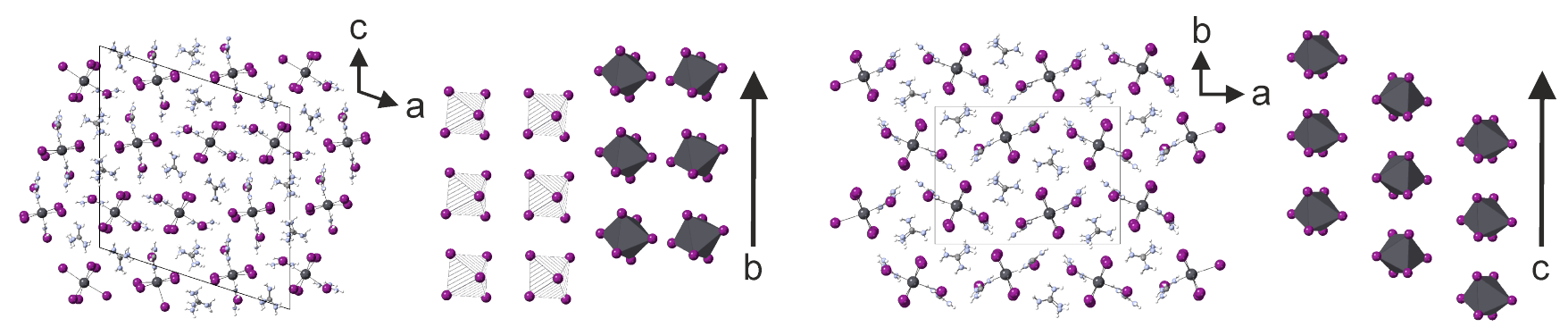

f) $\left(\mathrm{C}\left(\mathrm{NH}_{2}\right)_{3}\right) \mathrm{Pb}_{2} \mathrm{I}_{5} 5(298 \mathrm{~K})$

g) $\left(\mathrm{C}\left(\mathrm{NH}_{2}\right)_{3}\right) \mathrm{Pb}_{2} \mathrm{I}_{5} 5-\mathrm{II}(490 \mathrm{~K})$
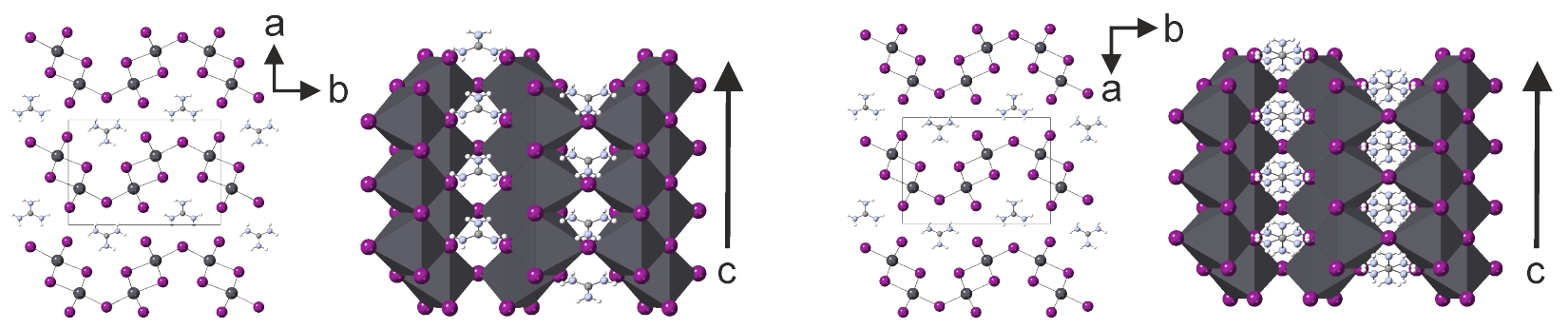

Figure 3: Structures of a) $\left(\mathrm{C}\left(\mathrm{NH}_{2}\right)_{3}\right) \mathrm{Pbl}_{3}$ 1, b) $\left(\mathrm{C}\left(\mathrm{NH}_{2}\right)_{3}\right)_{2} \mathrm{Pbl}_{4}$ 2, c) $\left(\mathrm{C}\left(\mathrm{NH}_{2}\right)_{3}\right)_{3} \mathrm{Pbl}_{5}$ 3, and d) $\left(\mathrm{C}\left(\mathrm{NH}_{2}\right)_{3}\right)_{4} \mathrm{Pbl}_{6} 4$, all at $298 \mathrm{~K}$. Reproduced with permission from ref. ${ }^{40}$; Copyright Wiley-VCH Verlag $\mathrm{GmbH}$ \& Co. KGaA. Also structures of the novel compounds e) $\left(\mathrm{C}\left(\mathrm{NH}_{2}\right)_{3}\right)_{4} \mathrm{Pbl}_{6} 4-\mathrm{Il}$ at $\left.370 \mathrm{~K}, \mathbf{f}\right)\left(\mathrm{C}\left(\mathrm{NH}_{2}\right)_{3}\right) \mathrm{Pb}_{2} \mathrm{I}_{5}$ 0.5 at $298 \mathrm{~K}$, and $\mathbf{g})\left(\mathrm{C}\left(\mathrm{NH}_{2}\right)_{3}\right) \mathrm{Pb}_{2} \mathrm{I}_{5} \mathbf{0 . 5}$-II at $490 \mathrm{~K}$; left unit cell with guanidinium-ions and $\mathrm{Pbl}_{6}$-octahedra; right connection of the $\mathrm{Pbl}_{6}$-octahedra within the crystal, for $\mathbf{f}$ ) and $\mathbf{g}$ ) shown together with the position of the guanidinium ions. Black: led, purple: iodine, lilac: nitrogen, gray: carbon, white: hydrogen. 


\section{Experimental section}

\subsection{Chemicals}

For the experiments lead(II) iodide $(99.99 \%, \mathrm{TCl}$, Germany) and guanidine hydroiodide (>97\%, $\mathrm{TCl}, \mathrm{Ger}-$ many) were used without further purification.

\subsection{Synthesis}

For the lab syntheses a vibration ball mill (Pulverisette 23, Fritsch $\mathrm{GmbH}$, Germany) was used. Lead(II) iodide and guanidine hydroiodide were loaded in a stainless steel jar $(10 \mathrm{~mL})$ with a total load of $500 \mathrm{mg}$. Three stainless steel balls (diameter: $7 \mathrm{~mm}$, weight: $1.4 \mathrm{~g}$ ) were added and the mixture was milled for $60 \mathrm{~min}$ at $40 \mathrm{~Hz}$.

The syntheses for the in situ investigations were conducted the same way, except that a custom made jar was used, which is described elsewhere. ${ }^{9}$ An additional rotation movement was applied with a speed of 0.25 rotations per seconds.

\subsection{Analytical techniques}

The PXRD measurements were conducted at the X04SA Materials Science (MS) beamline at the Swiss Light Source (SLS), Paul Scherrer Institute. ${ }^{41}$ For all measurements a monochromatic beam was employed (25.2 keV $\widehat{=} 0.49200 \AA$ ). A calibrated $\mathrm{LaB}_{6}$ standard was used to refine the exact wavelength.

The synthesis products were filled in glass capillaries and measured in transmission geometry using a 1D Mythen II microstrip detector. For the temperature studies additionally a Cryostream 800 (Oxford Cryosystems, United Kingdom) was installed to heat the sample.

The in situ setup for the the time-resolved investigation of mechanochemical reactions was described in detail elsewhere. ${ }^{9}$ For the calibration of the gained images the Dioptas program ${ }^{42}$ and for their integration the Bubble software ${ }^{43}$ were used. The acquisition time of a single measurement was $20 \mathrm{~s}$. For the full profile refinements of the PXRD data three succeeding images were merged. The experiments were carried out over a period of 2 years and a discussion about the comparability and reproducibility can be found in the supporting information. As described previously, with this setup and these kind of reactions, typical problems like inhomogenization and caking are negligible. ${ }^{40}$

Differential scanning calorimetry (DSC) experiments were carried on with a Netzsch DSC 204F1 thermal analysis instrument, in the temperature range from 293 to $428 \mathrm{~K}$. Measurements were performed on heating and cooling with a rate of $5 \mathrm{~K} \mathrm{~min}^{-1}$ using about $30 \mathrm{mg}$ of sample encapsulated in standard aluminium crucibles. An argon stream was used during the whole experiment as protective gas. A liquid nitrogen operated in a gaseous nitrogen mode was used during the experiment as a cooling medium. Prior the samples measurement the baseline of the two empty crucibles was determined.

\subsection{Structure solution and refinement}

The crystal structures of the compounds $\mathbf{1}, \mathbf{3}$ and $\mathbf{4}$, including high temperature phases for $\mathbf{1}$ and $\mathbf{3}$ were described previously. ${ }^{40}$ The crystal structure of 2 and its high temperature phases were described by Daub et al. ${ }^{44}$

The novel crystal structures of $\left(\mathrm{C}\left(\mathrm{NH}_{2}\right)_{3}\right)_{4} \mathrm{Pbl}_{6}$ at $370 \mathrm{~K}(4-\mathrm{II}),\left(\mathrm{C}\left(\mathrm{NH}_{2}\right)_{3}\right) \mathrm{Pb}_{2} \mathrm{I}_{5}$ at room temperature (0.5) and at $490 \mathrm{~K}(\mathbf{0 . 5}-\mathrm{II})$, which were all solved from PXRD data using the indexing, the charge flipping and the simulated annealing routine in Topas (version 6, Bruker AXS, Germany). The guanidinium ions were given as rigid bodies. During the heating the room temperature phase of $\left(\mathrm{C}\left(\mathrm{NH}_{2}\right)_{3}\right)_{4} \mathrm{Pbl}_{6} 4$ starts to undergo a phase transition and decompose into $\mathbf{3}$ and guanidine hydroiodide at the same time. For this reason the middle temperature phase 3-II and the high temperature phase of guanidine hydroiodide were used in the Rietveld refinement of 4-II. The gained ratio is: 4-II: $62 \%, 3-I I$ : $33 \%$, and high temperature phase of guanidine hydroiodide: $5 \%$. All Rietveld refinements were conducted in Topas. 
Table 1: Crystal data and structure refinement parameters of $\left(\mathrm{C}\left(\mathrm{NH}_{2}\right)_{3}\right)_{4} \mathrm{Pbl}_{6}$ 4-II $(370 \mathrm{~K}),\left(\mathrm{C}\left(\mathrm{NH}_{2}\right)_{3}\right) \mathrm{Pb}_{2} \mathrm{I}_{5}$ $0.5(298 \mathrm{~K})$ and $\left(\mathrm{C}\left(\mathrm{NH}_{2}\right)_{3}\right) \mathrm{Pb}_{2} \mathrm{I}_{5} \mathbf{0 . 5}-\mathrm{II}(490 \mathrm{~K})$.

\begin{tabular}{llll}
\hline & $\mathbf{4 - I I}$ & $\mathbf{0 . 5}$ & $\mathbf{0 . 5}-\mathbf{I I}$ \\
\hline Empirical formula & $\mathrm{C}_{4} \mathrm{~N}_{12} \mathrm{H}_{24} \mathrm{Pbl}_{6}$ & $\mathrm{CN}_{3} \mathrm{H}_{6} \mathrm{~Pb}_{2} \mathrm{I}_{5}$ & $\mathrm{CN}_{3} \mathrm{H}_{6} \mathrm{~Pb}_{2} \mathrm{I}_{5}$ \\
temperature $/ \mathrm{K}$ & 370 & 298 & 490 \\
color & white & yellow & yellow \\
Formula weight & 1208.95 & 1108.98 & 1108.98 \\
/g mol & & & \\
Crystal system & monoclinic & monoclinic & orthorhombic \\
Space group & $P 2_{1} / n$ & $P 2_{1} / m$ & $P m m n$ \\
$\mathrm{a} / \AA$ & $20.0571(2)$ & $10.9380(1)$ & $15.8967(4)$ \\
$\mathrm{b} / \AA$ & $14.7983(1)$ & $15.9036(2)$ & $4.5488(1)$ \\
$\mathrm{C} / \AA$ & $9.24592(9)$ & $4.53582(5)$ & $11.4039(3)$ \\
$\beta /{ }^{\circ}$ & $92.0933(9)$ & $91.2970(9)$ & 90 \\
$\mathrm{~V} / \AA^{3}$ & $2742.47(5)$ & $788.82(1)$ & $824.626(6)$ \\
$\mathrm{Z}$ & 4 & 2 & 2 \\
$\mathrm{D}_{\text {calc }} / \mathrm{g} \mathrm{cm}{ }^{-3}$ & $2.92801(5)$ & $4.66912(8)$ & $4.46636(3)$ \\
$\mathrm{R}_{\text {wp }}$ & 6.27 & 6.19 & 4.81 \\
$\mathrm{R}_{\text {Bragg }}$ & 2.92 & 2.47 & 2.48 \\
$\mathrm{GOF}$ & 3.51 & 6.76 & 2.90 \\
\hline
\end{tabular}

The full profile refinements of the time-resolved powder diffraction patterns were conducted in Topas. All phases used were refined once against a pattern containing mainly the desired phase to find the starting values. The final refinements were then conducted automatically with restrained cell parameters. The 2D plots of all conducted in situ investigations are shown in the supporting information.

Regarding the phases used in the refinements a slightly different approach than in our first publication was used. For 3 the room temperature (RT) and the middle temperature (MT) phase were used and for 4 the new discovered high temperature $(\mathrm{HT})$ phase was used. This let to a more reliable and stable automatic refinement. All the other phases were used as before - the room temperature phase for $\mathbf{1}$ and the middle temperature phase for $\mathbf{2}$. The new discovered phase $\mathbf{0 . 5}$ was only introduced into the refinement if its peaks were visible. As observed before, guanidinium hydroiodide undergoes a phase transition to its high temperature phase, which has a completely different pattern and is therefore listed separately.

CCDC 2034767-2034769 contain the supplementary crystallographic data for 4-II, $\mathbf{0 . 5}$ and $\mathbf{0 . 5}$-II. These data can be obtained free of charge from the Cambridge Crystallographic Data Centre via www.ccdc.cam.ac.uk/structures.

\section{Results and discussion}

\subsection{Novel structures}

The crystal data and refinement parameter for the new compounds $\left(\mathrm{C}\left(\mathrm{NH}_{2}\right)_{3}\right)_{4} \mathrm{Pbl}_{6} 4-\mathrm{II}(370 \mathrm{~K}),\left(\mathrm{C}\left(\mathrm{NH}_{2}\right)_{3}\right) \mathrm{Pb}_{2} \mathrm{I}_{5}$ $\mathbf{0 . 5}(298 \mathrm{~K})$ and $\left(\mathrm{C}\left(\mathrm{NH}_{2}\right)_{3}\right) \mathrm{Pb}_{2} \mathrm{I}_{5} \mathbf{0 . 5}$-II $(490 \mathrm{~K})$ are listed in Table 1. The respective Rietveld plots are shown in Figure S1 and S2 and selected bond length and angles are listed in table S1-S3.

The structure of $4-\mathrm{II}$ is shown in Figure $3 \mathrm{e}$. It consists of isolated and distorted $\mathrm{Pbl}{ }_{6}$-octahedra ( $\mathrm{d}_{\mathrm{Pb}-\mathrm{I}}$ $\left.=3.164(7)-3.297(7) \AA, L_{1-P b-1}=83.7(2)-102.2(2)^{\circ}\right)$. The guanidinium-ions are located between these octahedra and connect them via hydrogen bonds, with the shortest N-I distance at 3.2(1) $\AA$ (N31-I4). In opposite to the room temperature structure 4 only one type of $\mathrm{Pbl}_{6}$-octahedra is present in $\mathbf{4 - I I}$, which leads to the observed symmetry increase. Compared to 4 , the volume of the unit cell is halved and the space group change from $\mathrm{P} 2 / \mathrm{n}$ to $\mathrm{P} 21 / \mathrm{n}$ in $4-\mathrm{II}$.

Figure $3 \mathrm{f}$ shows the structure of $\left(\mathrm{C}\left(\mathrm{NH}_{2}\right)_{3}\right) \mathrm{Pb}_{2} \mathrm{I}_{5}$ 0.5. The distorted $\mathrm{Pbl}_{6}$-octahedra $\left(\mathrm{d}_{\mathrm{Pb}-\mathrm{I}}=3.156(3)\right.$ 
- 3.282(2) $\left.\AA, L_{1-\mathrm{Pb}-1}=84.21(6)-98.05(5)^{\circ}\right)$ are connected via their edges forming a double chain. These chains are then connected via one corner of a $\mathrm{Pbl}_{6}$-octahedra to form a zig-zag shaped layer. The guanidiniumions are located between the layers. They connect the layers only via weak hydrogen bonds, with the shortest one at a distance of $3.67(2) \AA(\mathrm{N} 2-13)$.

The structure of $\left(\mathrm{C}\left(\mathrm{NH}_{2}\right)_{3}\right) \mathrm{Pb}_{2} \mathrm{I}_{5} \mathbf{0 . 5}-\mathrm{II}$ is depicted in Figure $3 \mathrm{~g}$. The general structure did not change compared to the room temperature structure. The $\mathrm{Pbl}_{6}$-octahedra are now less distorted $\left(\mathrm{d}_{\mathrm{Pb}-\mathrm{I}}=3.170(1)\right.$ - 3.284(2) $\left.\AA, L_{1-P b-1}=86.603(3)-94.077(2)^{\circ}\right)$ and the guanidinium-ions are disordered. As a result the symmetry increase to orthorhombic.

Lead halides with a $\mathrm{A}^{+}\left[\mathrm{Pb}_{2} \mathrm{X}_{5}\right]^{-}$composition, like $\mathbf{0 . 5}$, are rare. Best to our knowledge, the only hybrid lead iodide so far was described by Elleuch et al. ${ }^{45}$ Pentylamine is used as cation and the formed $\mathrm{Pbl}_{6}$-octahedra are connected via their edges and corners, forming a double layer. Compounds containing either metals or ammonium ions and bromine are more common. In these compounds the lead has a higher coordination number than six. The inorganic polyhedra are forming layers or even three dimensional frameworks. ${ }^{46-49}$

\subsection{Mechanistic studies}

We aimed to rationalize the pathway of our mechanochemical process as observed data suggested a non-trivial process of interconversion, possibly underlaying a more complex kinetics and thermodynamics than previously reported. To gain understanding one should consider that the reaction pathways of a mechanochemical reaction are influenced by two main factors, energy of impacts and number of particle contacts. The maximum impact energy is proportional to the ball mass, and the square of the max velocity, which is directly proportional to the frequency used. The number of contacts describes how often reactive particles are brought into contact which each other by the impact of balls. The more often, the more the reaction is likely to happen. In neat grinding reactions the number of contacts is dependent on the shaking frequency but also on the surface of the milling balls. Normally, the compound distribution is plotted against the reaction time. However, by changing the frequency two parameters change, the energy and the number of contacts. Both parameters strongly influence the reaction. Since we use different frequencies in this study, we show additionally the compound distribution plotted against the vibration cycles, which we calculated out of the frequency and the time and which is roughly proportional to the number of contacts. By this approach it is possible to compare the reactions at different frequencies in dependence to the energy, since the mixing speed is normalized. ${ }^{31,50}$

Firstly, to change the mechanical energy provided to the system we simply tuned the shaking frequencies and observed the compound distribution against the time, as shown in Figure 4 at the top for the synthesis of 3. The change of frequency did not just change the speed of the reaction, but also its pathway. While the nucleation time of $\mathbf{3}$ is too fast to see any influence, the growth speed is clearly proportional to the frequency used. Since a higher frequency leads to a higher energy and convection this is the expected behavior. Also 4 nucleates earlier at higher frequencies. Its growth speed instead is only at $20 \mathrm{~Hz}$ slower and after that constant. It is worth noting the formation of $\mathbf{4}$ always stops, when guanidine hydroiodide is completely used. The amount of $\mathbf{4}$ which is formed intermediately is getting significantly lower at higher frequencies. The formation of 3 is strongly influenced by the formation of 4 : its production is either decelerated $(50 \mathrm{~Hz})$, stops $(40 \mathrm{~Hz})$ or is even reversed $(30 \mathrm{~Hz}$ and $20 \mathrm{~Hz})$. Additionally 1 and 2 are always formed as intermediates, while $\mathbf{0 . 5}$ is only observed at $20 \mathrm{~Hz}$. The high temperature phase of guanidine hydroiodide is formed much more at higher frequencies, which implies higher temperatures at higher milling frequencies, although we have previously shown that the higher frictional heat cannot be the only reason. ${ }^{40}$

If the increase of the frequency would just accelerate the reaction we should see the same pathway, just faster, as shown by several studies. ${ }^{31,51,52}$ Instead there are clear differences, which implies that the different parts of the reaction (see Figure 2) have different dependencies towards shaking frequency. The differences are getting more obvious by looking at the amounts plotted against the vibration cycles (Figure 4, bottom). The extremely fast nucleation of $\mathbf{3}$ stays similar while its growth gets faster, except at $50 \mathrm{~Hz}$, where it is similar. The nucleation of $\mathbf{4}$ instead needs less contacts at lower energies and is therefore inverse proportional to the energy. That a different milling frequency can also influence the reaction pathway was recently described for an organic condensation reaction and for the formation of ternary cocrystals. ${ }^{53,54}$

To better understand if the observed effects are based on the energy or, instead, on the number of contacts 

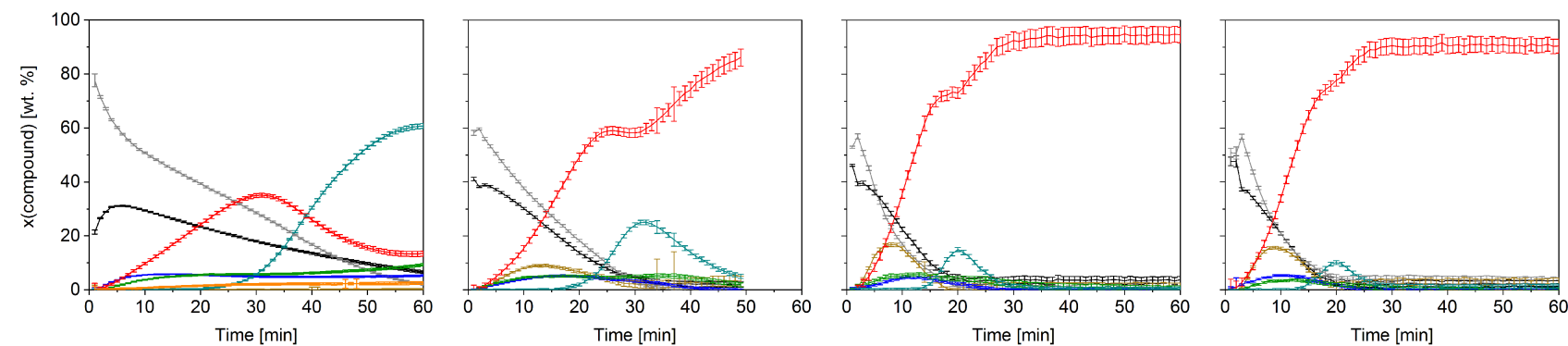

Synthesis of $3,20 \mathrm{~Hz}-50 \mathrm{~Hz}$, by vibration cycles
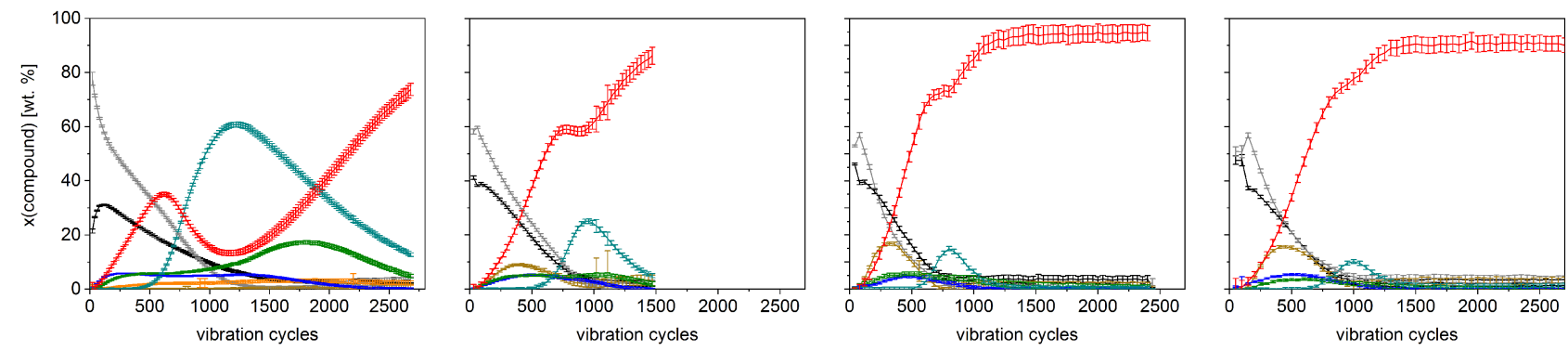

$\begin{array}{ll}-\mathrm{Pbl}_{2} & - \text { Gua.HI, } \mathrm{H} \\ - \text { Gua.HI } & -\mathrm{HGuaPbl}_{3}\end{array}$

- (HGua) $)_{2} \mathrm{Pbl}_{4} 2, \mathrm{MT}$ phase

- (HGua) ${ }_{3} \mathrm{Pbl}_{5} 3, \mathrm{RT}+\mathrm{MT}$ phase

- (HGua) $)_{4} \mathrm{Pbl}_{6} 4$, HT phase

- $\mathrm{HGuaPb}_{2} \mathrm{I}_{5} 0.5$

Figure 4: Time-resolved change of the amount of the given compounds for the in situ investigation of the synthesis of 3 at different frequencies, from left to right: $20 \mathrm{~Hz}, 30 \mathrm{~Hz}, 40 \mathrm{~Hz}, 50 \mathrm{~Hz}$. Top plotted against the time, Bottom plotted against the number of vibration cycles.

changing with the frequency, the synthesis was repeated with the idea to keep the kinetic energy of the balls roughly constant. For this reason the ball size and the frequency were varied. For smaller balls a higher frequency was used to keep the term $1 / 2 m \nu^{2}$ constant. The used parameter are shown in Table 2 . Beside the frequency also the area of the balls change. Recently, Boldyreva and co-workers have shown how big the impact is of the surface area for the reaction pathway. ${ }^{27,28}$ In our case, the increase of the surface per ball is bigger than the decrease in frequency, which is proportional to the mixing speed. We used three balls in every reaction, so the effect of the surface increase is enhanced. Since a higher surface offers as well the chance for more contacts, an increase of the reaction speed from the small to the big balls is expected, which should be even more pronounced by looking at the vibration cycles instead of the time. Table 2 lists the time and number of vibration cycles when the amount of 4 reaches for the first time $5 \%$. In fact, the expected trend is very true, the nucleation of $\mathbf{4}$ is much faster at slower frequencies, no matter if looked at the times or the contacts. But by looking at the plots in Figure 5 it is obvious that the reaction is not just accelerated but also shows different pathways. The biggest differences is the amount of produced 4. It goes slightly down from $46 \mathrm{~Hz}$ with $4 \mathrm{~mm}$ balls to $33 \mathrm{~Hz}$ with $5 \mathrm{~mm}$ balls and goes down a lot at $25 \mathrm{~Hz}$ with $6 \mathrm{~mm}$ balls. By looking at the amount of free guanidine hydroiodide which is available when 4 nucleates a clear correlation can be found. The amount of free guanidine hydroiodide however correlates with the formation of 3 . As listed in Table 2, also the nucleation of $\mathbf{3}$ starts earlier by using bigger ball sizes but lower frequencies, although here the effect is less evident.

In Figure 6 the percentage evolution of $\mathbf{3}$ and $\mathbf{4}$ are compared for the different reactions, respectively, to better highlight the differences. The plot against the vibration cycles shows that the growth speed of 3 is strongly correlated with the area. For 4 instead the shape of the gained distribution curves is almost constant, regardless which frequency and ball size is used. The point in time of the nucleation instead correlates strongly with the area. These different behaviors of $\mathbf{3}$ and $\mathbf{4}$ superimpose and as a result the observed reaction pathways occur.

The observations suggest that for $\mathbf{3}$ the formation after nucleation, i.e. the growth, and for $\mathbf{4}$ the nucleation is the rate determining step, since these are the parts which are influenced by the number of contacts and 
Table 2: Parameters for the synthesis of $\mathbf{3}$ with constant energy and selected points in time and amounts of 3 and 4 ; v.c. = vibration cycle.

\begin{tabular}{|c|c|c|c|c|c|c|c|c|}
\hline \multirow{2}{*}{$\begin{array}{l}\text { Fre- } \\
\text { quency } \\
{[\mathrm{Hz}]}\end{array}$} & \multirow{2}{*}{$\begin{array}{l}\text { Ball } \\
\text { size } \\
{[\mathrm{mm}]}\end{array}$} & \multirow{2}{*}{$\begin{array}{l}\text { Ball } \\
\text { mass } \\
{[\mathrm{mg}]}\end{array}$} & \multirow{2}{*}{$\begin{array}{l}\text { Ball } \\
\text { Surface } \\
{\left[\mathrm{mm}^{2}\right]}\end{array}$} & \multicolumn{3}{|c|}{4 at $5 \%$} & \multicolumn{2}{|c|}{3 at $5 \%$} \\
\hline & & & & $\begin{array}{l}\mathrm{t} \\
{[\mathrm{min}]}\end{array}$ & $\begin{array}{l}\mathrm{N} \\
{[\mathrm{v} . \mathrm{c} .]}\end{array}$ & $\begin{array}{l}x(\mathrm{Gua} \cdot \mathrm{HI}) \\
{[\%]}\end{array}$ & $\begin{array}{l}\mathrm{t} \\
{[\mathrm{min}]}\end{array}$ & $\begin{array}{l}\mathrm{N} \\
{\left[\begin{array}{ll}\mathrm{v} & \mathrm{c} .]\end{array}\right.}\end{array}$ \\
\hline 46 & 4 & 0.26 & 50 & 55 & 2530 & 23 & 10 & 460 \\
\hline 33 & 5 & 0.50 & 79 & 44 & 1452 & 21 & 9 & 297 \\
\hline 25 & 6 & 0.87 & 113 & 37 & 925 & 15 & 8 & 200 \\
\hline
\end{tabular}

${ }^{*}$ The values given are for one ball. In every synthesis three balls were used.

\section{Synthesis of $\mathbf{3}$, constant energy, by times}

$25 \mathrm{~Hz}, 6 \mathrm{~mm}$ balls

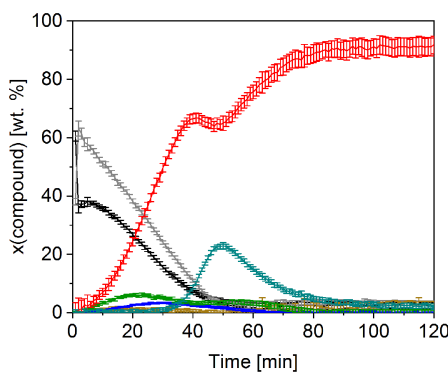

$33 \mathrm{~Hz}, 5 \mathrm{~mm}$ balls

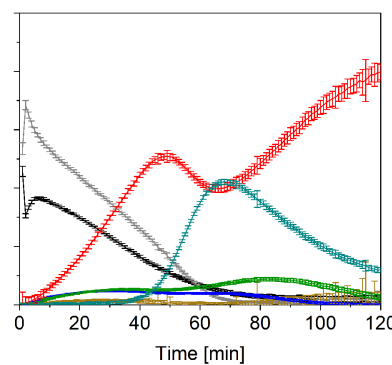

$46 \mathrm{~Hz}, 4 \mathrm{~mm}$ balls

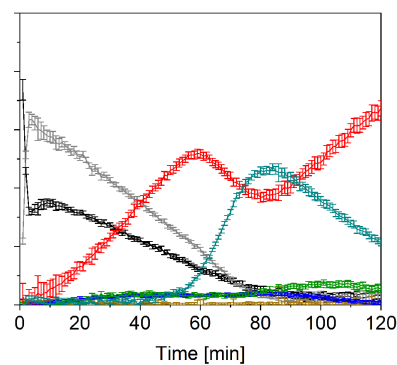

Synthesis of 3, constant energy, by vibration cycles

$25 \mathrm{~Hz}, 6 \mathrm{~mm}$ balls

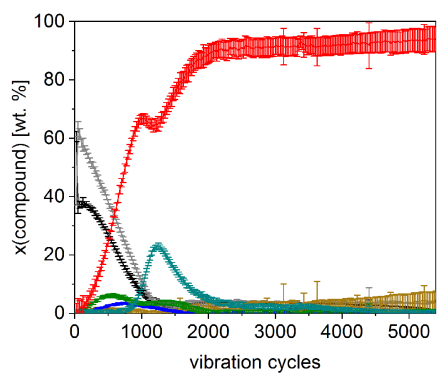

$33 \mathrm{~Hz}, 5 \mathrm{~mm}$ balls

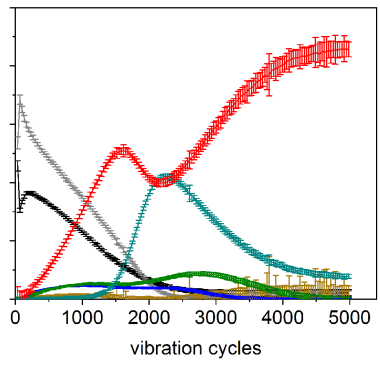

- (HGua) $)_{2} \mathrm{Pbl}_{4} 2$, MT phase

$$
\text { - Gua.HI } \quad-\mathrm{HGuaPbl}_{3} 1 \quad-\left(\mathrm{HGua}_{3} \mathrm{Pbl}_{5} 3, \mathrm{RT}+\mathrm{MT}\right. \text { phase }
$$

$46 \mathrm{~Hz}, 4 \mathrm{~mm}$ balls

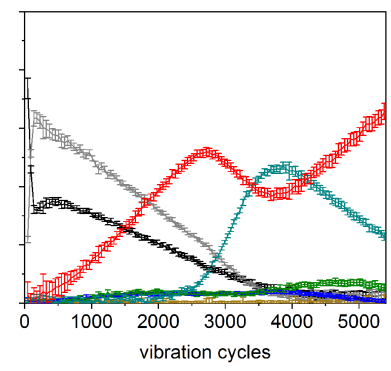

- $(\mathrm{HGua})_{4} \mathrm{Pbl}_{6} 4$, $\mathrm{HT}$ phase

Figure 5: Time-resolved change of the amount of the given compounds for the in situ investigation of the synthesis of $\mathbf{3}$ at constant energy but with varied milling frequencies and ball sizes. Top plotted against the time, Bottom plotted against the number of vibration cycles.

\section{Synthesis of $\mathbf{3}$, constant energy}
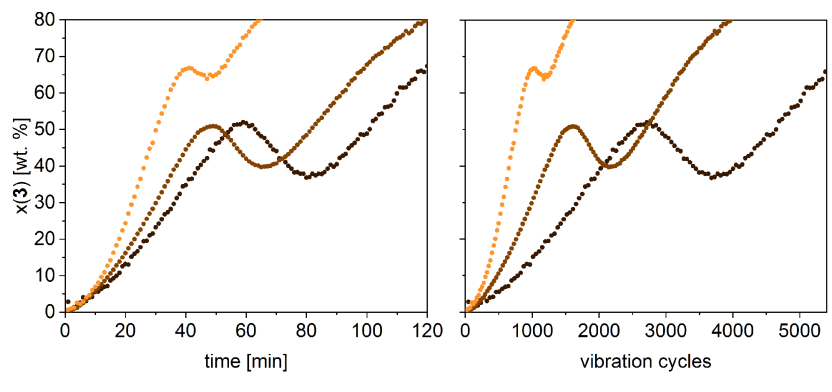

- $25 \mathrm{~Hz}, 6 \mathrm{~mm}$ balls

- $33 \mathrm{~Hz}, 5 \mathrm{~mm}$ balls
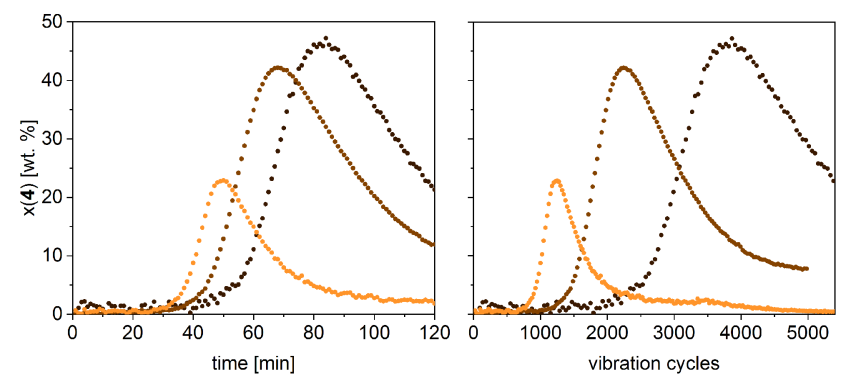

- $46 \mathrm{~Hz}, 4 \mathrm{~mm}$ balls

Figure 6: Time-resolved change of the amount of 3 (Left) and 4 (Right) in the synthesis of 3 with constant energy but varied milling frequency and ball size. 
Synthesis of $\mathbf{3}+2.5 \% \mathbf{4}, 20 \mathrm{~Hz}-50 \mathrm{~Hz}$, by times
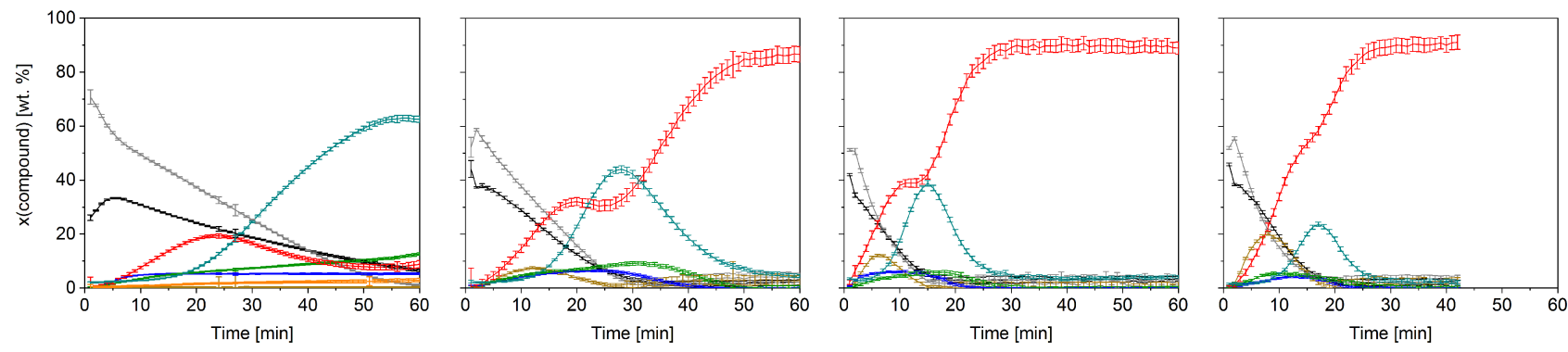

Synthesis of $3+2.5 \% 4,20 \mathrm{~Hz}-50 \mathrm{~Hz}$, by vibration cycles
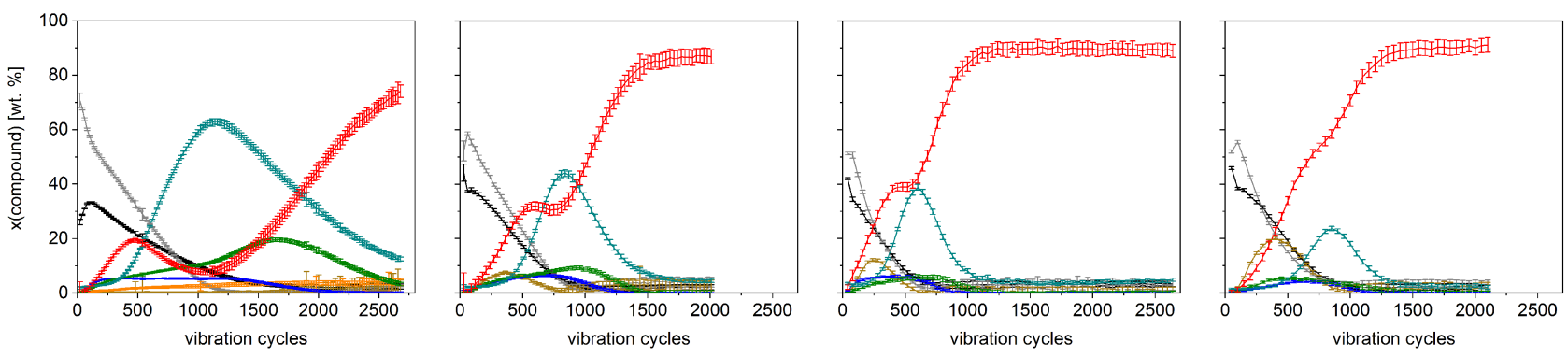

$$
\begin{array}{llll}
-\mathrm{Pbl}_{2} & - \text { Gua } \cdot \mathrm{HI}, \mathrm{HT} \text { phase } & -\left(\mathrm{HGua}_{2} \mathrm{Pbl}_{4} 2, \mathrm{MT}\right. \text { phase } & -(\mathrm{HGua})_{4} \mathrm{Pbl}_{6} 4, \mathrm{HT} \text { phase } \\
- \text { Gua.HI } & -\mathrm{HGuaPbl}_{3} 1 & -\left(\mathrm{HGua}_{3} \mathrm{Pbl}_{5} 3, \mathrm{RT}+\mathrm{MT}\right. \text { phase } & -\mathrm{HGuaPb}_{2} \mathrm{I}_{5} 0.5
\end{array}
$$

Figure 7: Time-resolved change of the amount of the given compounds for the in situ investigation of the synthesis of $\mathbf{3}$ with $2.5 \%$ of $\mathbf{4}$ added to the reaction mixture at different frequencies, from left to right: $20 \mathrm{~Hz}$, $30 \mathrm{~Hz}, 40 \mathrm{~Hz}, 50 \mathrm{~Hz}$. Top plotted against the time, Bottom plotted against the number of vibration cycles.

Synthesis of $\mathbf{3}$, with and without seeding with $\mathbf{4}$
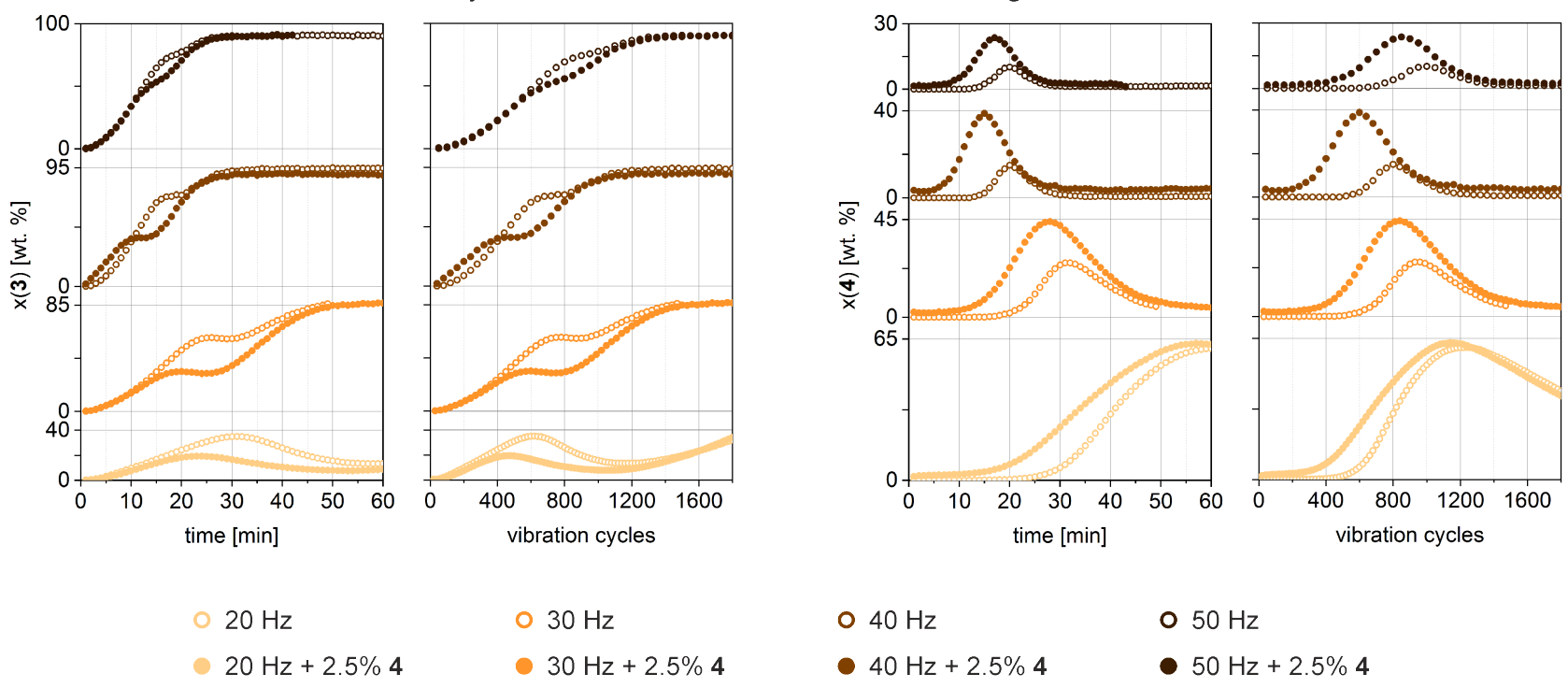
○ $30 \mathrm{~Hz}$
- $30 \mathrm{~Hz}+2.5 \% 4$

○ $40 \mathrm{~Hz}$

- $50 \mathrm{~Hz}$

- $40 \mathrm{~Hz}+2.5 \% 4$

- $50 \mathrm{~Hz}+2.5 \% 4$

Figure 8: Time-resolved change of the amount of $\mathbf{3}$ (Left) and $\mathbf{4}$ (Right) in the synthesis of $\mathbf{3}$ with and without seeding with 4 . 
Table 3: Comparison of selected amounts of 4 and Gua $\cdot H I, H T+R T$ at selected points in time between the synthesis of 3 without and with the addition of $2.5 \%$ of 4 .

\begin{tabular}{|c|c|c|c|c|c|c|c|c|}
\hline Synthesis & $20 \mathrm{~Hz}$ & $\begin{array}{l}20 \mathrm{~Hz} \\
+4\end{array}$ & $30 \mathrm{~Hz}$ & $\begin{array}{l}30 \mathrm{~Hz} \\
+4\end{array}$ & $40 \mathrm{~Hz}$ & $\begin{array}{l}40 \mathrm{~Hz} \\
+4\end{array}$ & $50 \mathrm{~Hz}$ & $\begin{array}{l}50 \mathrm{~Hz} \\
+4\end{array}$ \\
\hline time at $+5 \% 4[\mathrm{~min}]$ & 29 & 20 & 22.5 & 14.5 & 16 & 7 & 17 & 11 \\
\hline vibration cycles at $+5 \% 4$ & 580 & 400 & 675 & 435 & 640 & 280 & 850 & 550 \\
\hline$x($ Gua $\cdot \mathrm{HI}, \mathrm{HT}+\mathrm{RT})$ at $+5 \% 4[\%]$ & 30 & 37 & 14 & 28 & 5 & 22 & 7 & 12 \\
\hline Maximal amount of $4[\%]$ & 61 & 63 & 25 & 44 & 15 & 39 & 20 & 24 \\
\hline
\end{tabular}

the energy. To support these finding we repeated the standard synthesis of 3 at the same frequencies $(20 \mathrm{~Hz}$, $30 \mathrm{~Hz}, 40 \mathrm{~Hz}, 50 \mathrm{~Hz})$ but added $12.5 \mathrm{mg}(2.5 \%)$ of 4 to the reaction mixture. The resulting reaction pathways are shown in Figure 7. A clear seeding effect can be observed, the formation of 4 starts earlier in all four reactions compared to the reactions without the seed. Figure 8 provides a direct comparison of the percentage evolution of $\mathbf{3}$ and $\mathbf{4}$ in the synthesis of $\mathbf{3}$ at different frequencies with and without seeding. In Table 3 some distinctive points of both synthesis series are listed. The addition of the seeds leads to an earlier nucleation of $\mathbf{4}$ and therefore more free guanidine hydroiodide is available and a higher amount of $\mathbf{4}$ is formed. Also the formation of $\mathbf{3}$ is interrupted earlier. However, as expected the seeding does not influence the interplay of the phases. The formation of 3 is still decelerated at $50 \mathrm{~Hz}$, stops at $40 \mathrm{~Hz}$ and is reversed at $30 \mathrm{~Hz}$ and $20 \mathrm{~Hz}$. Also the trend that the nucleation time of 4 is getting faster by time but need more contacts at higher energies, and is therefore negative energy dependent, is repeated. The results show that seeding is only influencing the nucleation of 4 and nothing else.

We also conducted the synthesis of 3 at $40 \mathrm{~Hz}$ with the doubled amount $(25 \mathrm{mg}, 5 \%)$ of 4 and other additives (always $12.5 \mathrm{mg}, 2.5 \%$ ), namely $\mathbf{1}, \mathbf{2}$, and $\mathbf{2}$ and 4 together $(12.5 \mathrm{mg}$, respectively). A detailed description and the resulting plots of the percentage evolution are shown in the supporting information (Figure S4). The results proof that only the addition of $\mathbf{4}$ initiates a seeding effect, while the other additives just act as additional reaction partners.

For a better understanding of the observed reaction pathways and the complex interplay of $\mathbf{3}$ and $\mathbf{4}$, we tried to divide the whole reaction in its single parts (Figure 2, r1, r2, r3). A comparison of the standard synthesis of $\mathbf{4}$ with the same synthesis with additional $2.5 \%$ of $\mathbf{4}$ shows that in both cases $\mathbf{3}$ is formed (Figure S5). Although the nucleation of 4 starts earlier, the overall reaction speed is not accelerated. This suggest that in $r 2$ the formation of 4 is not done by a reaction of the starting materials but by the reaction of 3 and guanidine hydroiodide. For $r 3$, i.e. the formation from 3 out of $\mathbf{4}$, there are two possible ways. 4 can either react with the also formed 2 or with lead(II) iodide. We conducted both reactions at two different frequencies. A detailed description and the resulting plots of the percentage evolution can be found in the supporting information (FigureS6). While the reaction of $\mathbf{4}$ with $\mathbf{2}$ goes directly towards $\mathbf{3}$ without intermediate formation, the reaction of $\mathbf{4}$ with lead(II) iodide is slower and $\mathbf{2}$ gets formed during the process. These results suggest that the essential reaction to form $\mathbf{3}$ via $\mathrm{r} 3$ is the one between $\mathbf{4}$ and $\mathbf{2}$.

To see the different dependencies of the partial reactions $r_{2}$ and $r_{3}$ both were conducted at different frequencies $(20 \mathrm{~Hz}, 30 \mathrm{~Hz}, 40 \mathrm{~Hz}, 50 \mathrm{~Hz})$. A comparison of the phase distributions over the number of vibration cycles is depicted in Figure 9 . At every frequency $r_{2}(3+$ guanidine hydroiodide $)$ has an initiating phase before the reaction starts. This phase is getting longer with higher energies, so at lower energies less contacts are needed for the nucleation. As observed before, the nucleation of 4 is inverse proportional to energy used. The growth of the phase afterward is independent of the energy. The formation of $\mathbf{3}$ out of $\mathbf{4}$ and $2\left(r_{3}\right)$ has only a small initiating phase, which gets even smaller at higher energies. Also the growth of this phase accelerate at higher energies. Based on these results the gained pathways for the standard synthesis of $\mathbf{3}$ and for the synthesis seeded with $\mathbf{4}$ can be explained as the result of the superimposing of the three different partial reactions.

Based on our gained knowledge that $\mathbf{3}$ is favored by higher energies while $\mathbf{4}$ is the opposite, we reinvestigated a phenomena observed in the synthesis of $\mathbf{3}$. As mentioned in our previous paper, the lab synthesis of $\mathbf{3}$ sometimes lead to $\mathbf{4}$ and $\mathbf{2}$ as products instead of $\mathbf{3}$. We assumed that this is the result of a decomposition 
Synthesis of $4(\mathbf{3}+\mathrm{Gua} \cdot \mathrm{HI}), 20 \mathrm{~Hz}-50 \mathrm{~Hz}$, by vibration cycles
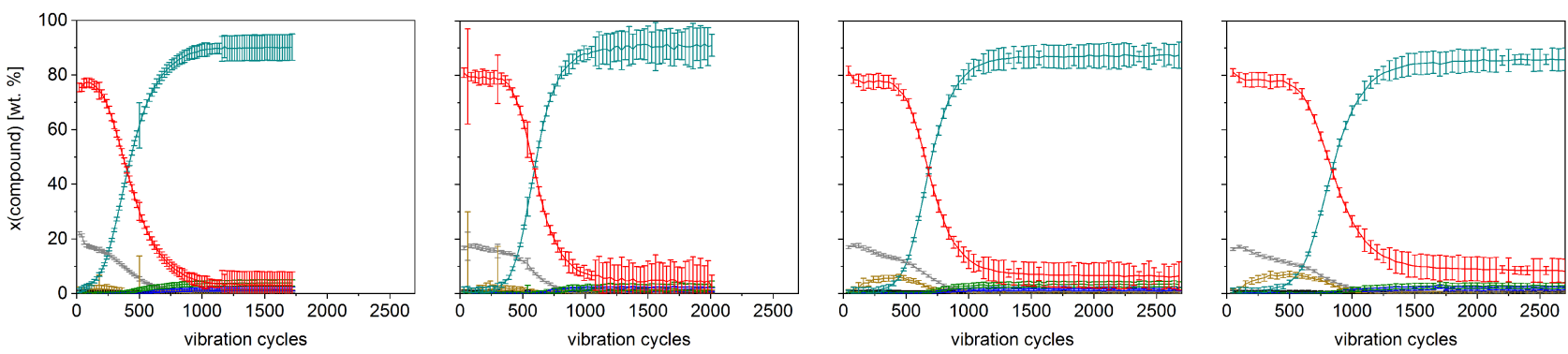

Synthesis of $3(\mathbf{4}+\mathbf{2}), 20 \mathrm{~Hz}-50 \mathrm{~Hz}$, by vibration cycles
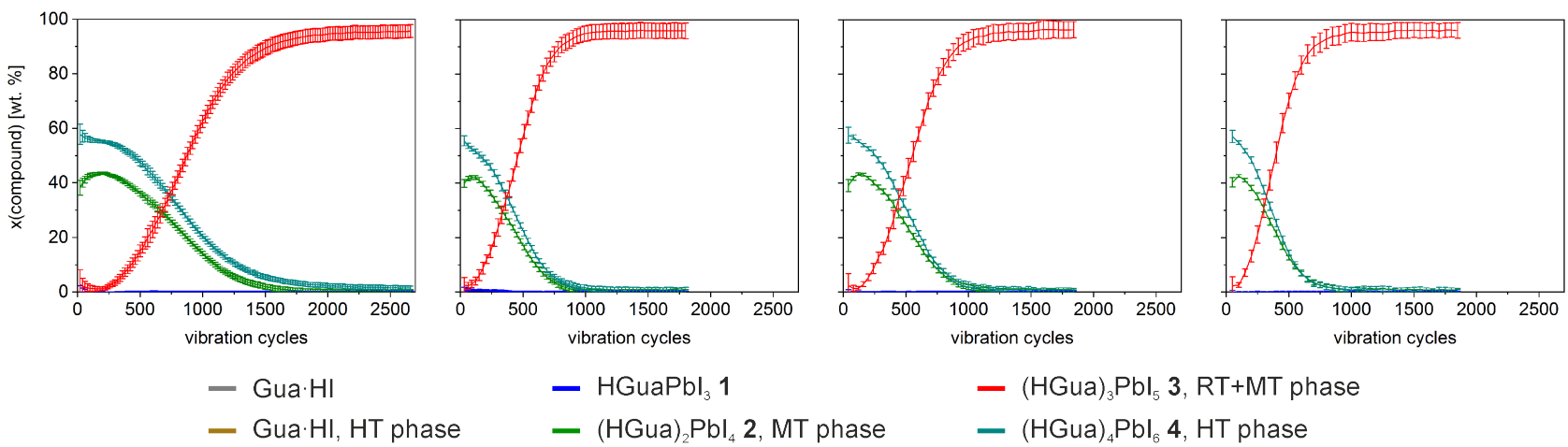

- (HGua) ${ }_{3} \mathrm{Pbl}_{5}$ 3, RT+MT phase

- $\mathrm{HGuaPbl}_{3} 1$

- (HGua) ${ }_{2} \mathrm{Pbl}_{4}$ 2, MT phase

- (HGua) ${ }_{4} \mathrm{Pbl}_{6} 4$, HT phase

Figure 9: Time-resolved change of the amount of the given compounds for the in situ investigation of the synthesis (Top) $\mathbf{4}$ by the reaction of $\mathbf{3}$ and guanidine hydroiodide and (Bottom) of $\mathbf{3}$ by the reaction of $\mathbf{4}$ and 2, at different frequencies, from left to right: $20 \mathrm{~Hz}, 30 \mathrm{~Hz}, 40 \mathrm{~Hz}, 50 \mathrm{~Hz}$.

and monitored ex situ the development of the crystalline phases of the produced $\mathbf{3}$ with time. Therefore the standard synthesis was repeated two times, 15 days and 10 days before the measurement. A portion of the material was used to fill two capillaries and to be stored in a vial. Six days and three days before the measurement the remaining powder was milled again and also filled in two capillaries and a vial, respectively. The last remaining powder was then milled once again one day before the measurement. In order to avoid any secondary reactions, all capillaries were filled without further grinding. Figure 10 shows a comparison of the powder patterns of both series. After 15 days and 10 days in any case $\mathbf{3}$ is decomposed to $\mathbf{4}$ and $\mathbf{2}$, while after one day 3 is almost pure. At the other timings all three phases can be detected but the ratio is strongly varying between the different samples. Since they are stemming from a milled sample it is unlikely that this effect is based on inhomogeneities, rather it shows that the decomposition is a spontaneous process. These results are consistent to the found energy dependencies: in fact a certain energy impact is required to favour the formation of $\mathbf{3}$, as previously described.

This phenomena could also be exemplified by heating a 1:1 mixture of 2 and $\mathbf{4}$ stepwise from $302 \mathrm{~K}$ to $500 \mathrm{~K}$. The respective powder patterns are depicted in Figure $11 \mathrm{a}$. At $382 \mathrm{~K} \mathrm{2-II}$ and 4 react to 3 . In the next steps the reflections of 4 vanish completely and of 2-II almost completely. The corresponding differential scanning calorimetry (DSC) curve is shown to the right. While the transformation from $\mathbf{2}$ to $\mathbf{2}-\mathrm{II}$, which is supposed to happen at about $307 \mathrm{~K}$, is not visible, a small endothermic peak at $353 \mathrm{~K}$ shows the transformation to 2-III, according to the temperatures found by Daub et al. ${ }^{44} \mathrm{~A}$ second, intense endothermic peak has its maximum at $373 \mathrm{~K}$; at this point the reaction between 2 and $\mathbf{4}$ is happening. The calculated energy of this endothermic process is $11.5 \mathrm{~kJ} \mathrm{~mol}^{-1}$, based on the molar weight of 3 . A shoulder at $390 \mathrm{~K}$ could be based on the transformation of $\mathbf{3}$ to $\mathbf{3}-\mathbf{I I}$. Since the backward reaction is a slow process, no signal assigned with that process is visible in the cooling curve. The very broad exothermic peak at $337 \mathrm{~K}$ could be based instead on the backwards transformation from 3-II to 3 .

The preference for $\mathbf{3}$ at higher energies is so strong that even pure $\mathbf{4}$ decomposes at higher temperatures into 3 and Gua. HI. Figure 11b shows the gained powder patterns when 4 was heated stepwise from $300 \mathrm{~K}$ to $400 \mathrm{~K}$. As described above for the high-temperature phase of 4 , at $370 \mathrm{~K} 4$ transforms to $4-1 \mathrm{Il}$ and at the 

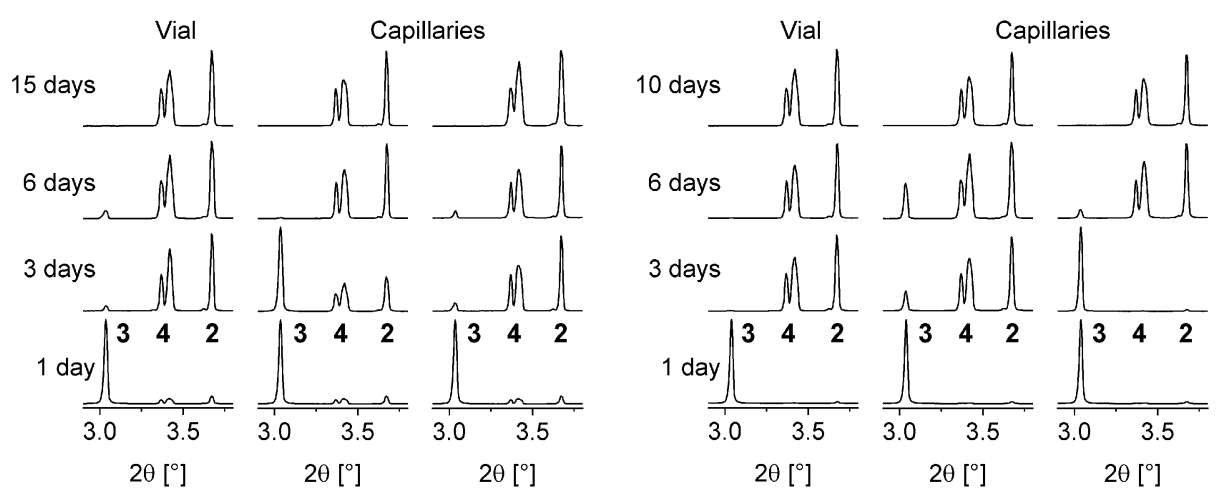

Figure 10: Comparison of powder patterns of the product of the standard synthesis of $\mathbf{3}$ after different times. There where two series (left and right), where the reaction was conducted, some sample taken and the powder at a different time was milled again to reproduce 3 . The measurement at one day is the same for all within a series. The intensity is normalized to the most intense peak.

a) Heating of $2+4$

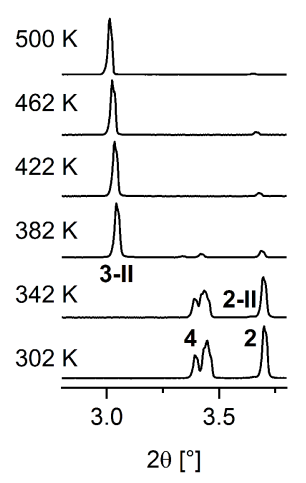

b) Heating of 4

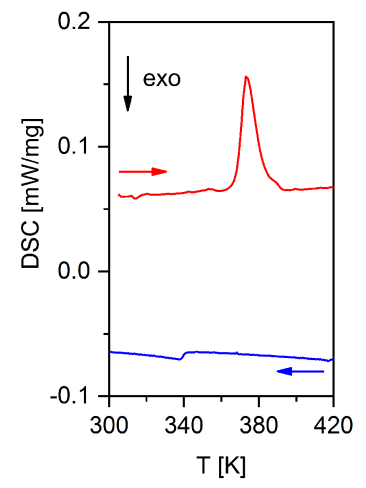

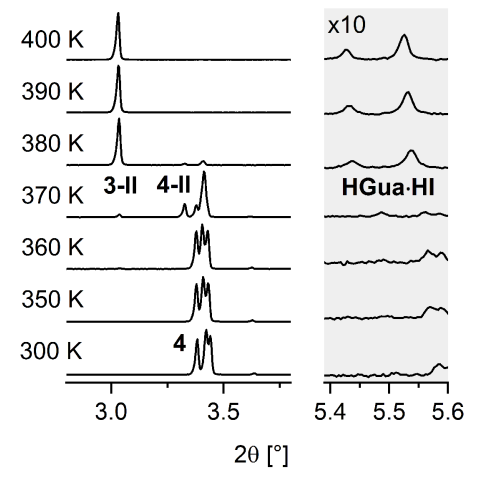

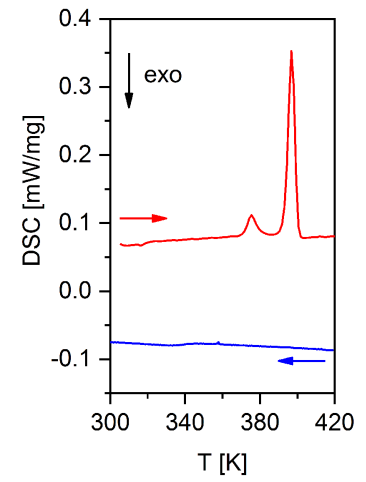

Figure 11: Powder patterns (left) and DSC baseline corrected signal curves (right) gained from a) the heating of a $1: 1$ mixture of $\mathbf{2}$ and $\mathbf{4}$ and $\mathbf{b}$ ) the heating of $\mathbf{4}$. For the powder patterns the intensity is normalized to the most intense peak. In the gray colored area the intensity is increased tenfold. The DSC curves were recorded upon heating (red) and cooling (blue) with a sweeping rate of $5 \mathrm{~K} \mathrm{~min}^{-1}$.

same time starts to decompose. At $390 \mathrm{~K}$ the process is complete. In no mechanochemical reaction where the given stoichiometry was the fitting one for $\mathbf{4}$ a direct decomposition of the compound into $\mathbf{3}$ and Gua $\cdot \mathrm{HI}$ could be observed. However, in the reaction series of $\mathbf{3}+\mathrm{Gua} \cdot \mathrm{HI}$ (Figure 9 Top) the residual amount of $\mathbf{3}$ after one hour increases with the frequency, and therefore with the energy, from $3.6 \%$ to $8.3 \%$. This suggests that with higher energy a decomposition of $\mathbf{4}$ is possible mechanochemically. The DSC measurement for this process is depicted in the same Figure. The DSC curve shows two endothermic peaks during the heating. The first one is at $376 \mathrm{~K}$ and can be associated to the phase transformation from 4 to 4-II. Shortly after, at $397 \mathrm{~K}$ a strong second peak can be observed which can be attributed to the decomposition of 4 into 3 and Gua. HI. The calculated energy is $17.3 \mathrm{~kJ} \mathrm{~mol}^{-1}$, based on the molar weight of 4 . All temperatures are in good agreement with our results from the high-temperature PXRD measurements. The DSC shows that the phase transformation of $\mathbf{4}$ and its decomposition are independent, separate processes. When cooling the produced mixture, a small endothermic peak at $357 \mathrm{~K}$ appears. It can be assigned to the transformation from 2-III to 2-II.

The change from 3 to 4 is a thermodynamically driven process. As observed in the ex situ study, 3 is metastable, while the thermodynamic stable state is instead the mixture of $\mathbf{2}$ and $\mathbf{4}$. The energy, provided thermally or in the non-equilibrium solid state mechanochemical reaction is stabilizing this metastable state. The conversion of $\mathbf{3}$ back to $\mathbf{2}$ and $\mathbf{4}$ is happening at room temperature within a few days, therefore the energy 


$$
\begin{aligned}
& \mathrm{n} \mathrm{Gua} \cdot \mathrm{HI}+\mathrm{Pbl}_{2} \stackrel{\mathrm{r}_{1}}{\longrightarrow} 3 \underset{\mathrm{n}=3,4}{\stackrel{\mathrm{r}_{3}}{\rightleftarrows}} 4
\end{aligned}
$$

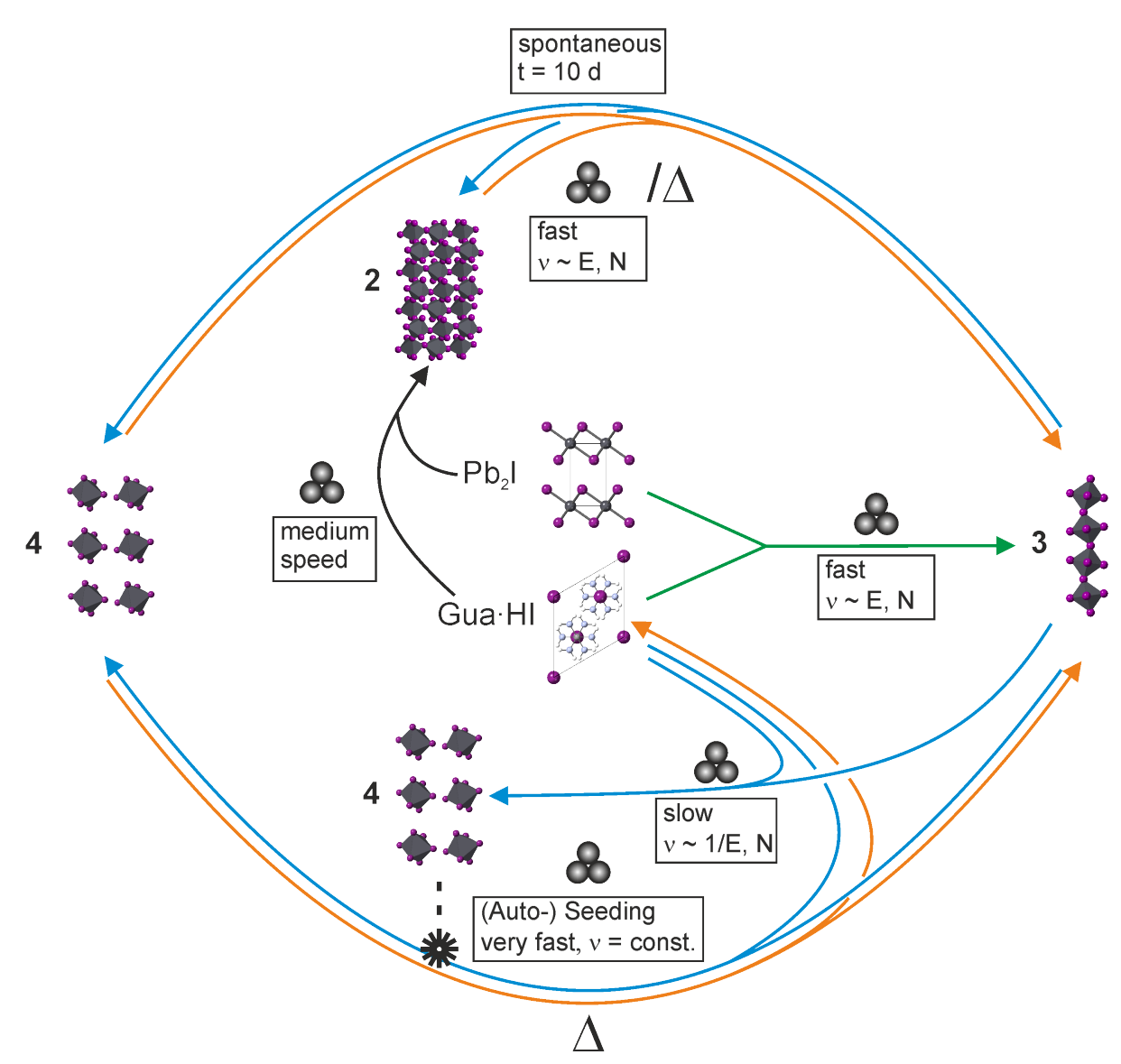

Figure 12: Schematic overview of the found reaction mechanism for the formation of $\mathbf{3}$ and $\mathbf{4}$ from the reaction $\mathrm{Pbl}_{2}+n \mathrm{Gua} \cdot \mathrm{HI}$ with $\mathrm{n}=3,4$. $\mathrm{E}$ - energy input during the milling, influenced by frequency and ball mass, $\mathrm{N}$ - number of contacts, influenced by frequency and surface area of the milling balls.

barrier for this reaction is relatively low, possibly because $\mathbf{4}$ can act as a catalyst. The fact that $\mathbf{4}$ itself also decomposes at not very high temperatures implies that the two energetic states are not very different in their total energy. Mechanochemistry allows to switch between the two energetic states (corresponding to $\mathbf{2}+\mathbf{4}$ or 3), leading to non-equilibrium products. The mechanical energy is changed into chemical energy which is stored within the product and later released spontaneously.

Figure 12 shows our gained possible reaction mechanism. Most favorable guanidine hydroiodide reacts with lead(II) iodide to $\mathbf{3}$ in a fast reaction. In a very slow, inverse energy dependent reaction $\mathbf{3}$ reacts with more guanidine hydroiodide to $\mathbf{4}$. When a critical amount of $\mathbf{4}$ is produced or in the presence of $\mathbf{4}, \mathbf{3}$ still reacts with more guanidine hydroiodide to 4 , but now this reaction is tremendously accelerated and energy independent. With 2, produced in the meanwhile or added to the mixture, 4 reacts in a fast process to 3 . But without the milling $\mathbf{3}$ decompose over time to $\mathbf{4}$ and $\mathbf{2}$ again. By applying of heat, $\mathbf{4}$ and $\mathbf{2}$ can react to 3. Additionally, $\mathbf{4}$ starts to decompose into 3 and guanidine hydroiodide at about $370 \mathrm{~K}$.

Seeding-assisted grinding is a known but not widely described phenomena. Most studies focus on organic polymorphs. By adding either a small amount of a molecule which is not involved in the reaction or a small amount of the wanted product, the reaction can be guided to produce the designated polymorph. ${ }^{55-58}$ In our case we have compounds of different stoichiometry not polymorphs and the seeding does not change the endproduct. Although $\mathbf{3}$ is not stable under normal conditions, it is the product of the synthesis with a ratio 
of 1:3, even when a huge amout of 4 is produced. In our previous paper we suggested that the observed reaction pathways are connected to the structures of the compounds. For $\mathbf{4}$ we assumed that the construction of the highly charged $\mathrm{Pbl}_{6}{ }^{4-}$-octahedra takes longer and also that a critical amount of these units has to be build to form and detect the crystal, which is why 4 nucleates so lately. The growing afterward is just an arrangement of the single units, guided by the highly charged octahedra attraction to the guanidinium ions, which results in a high growth speed. In the light of our new results, these assumptions need to be updated. The formation of the $\mathrm{Pbl}_{6}{ }^{4-}$-octahedra is not a separate, independent process. Instead, a small amount of 4 added to the reaction increases the nucleation speed and therefore the formation of more $\mathrm{Pbl}_{6}{ }^{4-}$-octahedra. As shown above, $\mathbf{4}$ is not formed from the starting materials but from 3. 4 provides higher charged particles in the inorganic moiety and the shortest hydrogen bonds. Likely this environment attracts and directs $\mathbf{3}$ and free guanidine hydroiodide. Only the coordination of one more $\mathrm{I}^{-}$-ion is needed to change the inorganic structure in 3 from a $1 \mathrm{D}$ chain to isolated $\mathrm{Pbl}_{6}{ }^{4-}$-octahedra. Therefore the construction of 4 is probably a continuous, auto catalytic process, which reaches after a certain amount a maximum growth speed. This could also be the reason for the instability of $\mathbf{3}$. Traces of $\mathbf{4}$ are more and more catalyzing its decomposition. On the contrary to the seldom described seeding effects, a lot of mechanochemical reactions have an activation time where no phase change is happening, but when they start they are very fast. Based on our results, it would be interesting to see if there seeding would help to speed up the reaction and lower the needed milling times. This would make mechanochemistry even more suitable for nowadays requirements of a green chemistry.

\section{Conclusions}

We conducted a comprehensive analysis of a complex mechanochemical process. Based on the conducted in situ investigations we could formulate a mechanism for the mechanochemical synthesis of $\left(\mathrm{C}\left(\mathrm{NH}_{2}\right)_{3}\right)_{3} \mathrm{Pbl}_{5} 3$ and $\left(\mathrm{C}\left(\mathrm{NH}_{2}\right)_{3}\right)_{4} \mathrm{Pbl}_{6} 4$. By conducting the syntheses of $\mathbf{3}$ at different frequencies, energies and by splitting the reaction into its single parts $\left(r_{1}, r_{2}\right.$, and $\left.r_{3}\right)$, we could prove that the formation of $\mathbf{3}$ is simply dependent on the energy and mixing speed. 4 instead shows an unusual behavior. Its nucleation is slightly negative dependent on the energy but dependent on the mixing speed, while the crystal growth is mostly independent of any influence. Since the nucleation of $\mathbf{4}$ is the rate determining step, we were able to influence the reaction pathway by seeding the mixture with a small amount of powdery 4 . In the light of these results, the decomposition of 3 into 2 and $\mathbf{4}$ within 10 days can be explained. The formation of $\mathbf{4}$ is thermodynamically favored and very likely an auto-catalytic process. We could describe in detail how mechanochemistry, instead, offers different thermodynamic conditions due to the non-equilibrium conditions of the reactions and can therefore stabilize metastable phases like 3. Our findings also highlight an important parameter in seeding-assisted grinding, which could be a useful tool to influence mechanochemical reactions and increase the attractiveness of this method for industrial applications.

\section{Acknowledgement}

The authors are grateful for the funding received from the European Union's Horizon 2020 research and innovation programme under the Marie Skłodowska-Curie grant agreement No 701647.

\section{Supporting information}

Supporting information available containing Rietveld plots and tables with selected bond lengths and angles for 4-II, 0.5, and 0.5-II, additional plots and descriptions for the in situ investigations, as mentioned in the text, and 2D plots of all conducted in situ investigations, ordered and arranged as their respective time-resolved plot of the compound distribution appear in the main text. 


\section{References}

[1] V. V. Boldyrev and K. Tkacova. Mechanochemistry of solids: Past, present, and prospects. J. Mater. Synth. Process., 8(3-4):121-132, 2000.

[2] L. Takacs. The historical development of mechanochemistry. Chem. Soc. Rev., 42(18):7649-7659, 2013.

[3] T. Friscic. Supramolecular concepts and new techniques in mechanochemistry: Cocrystals, cages, rotaxanes, open metal-organic frameworks. Chem. Soc. Rev., 41(9):3493-3510, 2012.

[4] P. Balaz, M. Achimovicova, M. Balaz, P. Billik, Z. Cherkezova-Zheleva, J. M. Criado, F. Delogu, E. Dutkova, E. Gaffet, F. J. Gotor, R. Kumar, I. Mitov, T. Rojac, M. Senna, A. Streletskii, and K. Wieczorek-Ciurowa. Hallmarks of mechanochemistry: from nanoparticles to technology. Chem. Soc. Rev., 42(18):7571-7637, 2013.

[5] A. A. Geciauskaite and F. Garcia. Main group mechanochemistry. Beilstein J. Org. Chem., 13:2068-2077, 2017.

[6] D. Tan and T. Friscic. Mechanochemistry for organic chemists: An update. Eur. J. Org. Chem., 2018(1):18-33, 2018.

[7] J. Huot, F. Cuevas, S. Deledda, K. Edalati, Y. Filinchuk, T. Grosdidier, B. C. Hauback, M. Heere, T. R. Jensen, M. Latroche, and S. Sartori. Mechanochemistry of metal hydrides: Recent advances. Materials, 12(17), 2019.

[8] T. Friscic, I. Halasz, P. J. Beldon, A. M. Belenguer, F. Adams, S. A. J. Kimber, V. Honkimaki, and R. E. Dinnebier. Real-time and in situ monitoring of mechanochemical milling reactions. Nat. Chem., 5(1):66-73, 2013.

[9] V. Ban, Y. Sadikin, M. Lange, N. Tumanov, Y. Filinchuk, R. Černý, and N. Casati. Innovative in situ ball mill for x-ray diffraction. Anal. Chem., 89(24):13176-13181, 2017.

[10] X. H. Ma, W. B. Yuan, S. E. J. Bell, and S. L. James. Better understanding of mechanochemical reactions: Raman monitoring reveals surprisingly simple 'pseudo-fluid' model for a ball milling reaction. Chem. Commun., 50(13):1585-1587, 2014.

[11] H. Kulla, M. Wilke, F. Fischer, M. Rollig, C. Maierhofer, and F. Emmerling. Warming up for mechanosynthesis - temperature development in ball mills during synthesis. Chem. Commun., 53(10):1664-1667, 2017.

[12] K. Uzarevic, N. Ferdelji, T. Mrla, P. A. Julien, B. Halasz, T. Friscic, and I. Halasz. Enthalpy vs. friction: heat flow modelling of unexpected temperature profiles in mechanochemistry of metal-organic frameworks. Chem. Sci., 9(9):2525-2532, 2018.

[13] L. Batzdorf, F. Fischer, M. Wilke, K. J. Wenzel, and F. Emmerling. Direct in situ investigation of milling reactions using combined x-ray diffraction and raman spectroscopy. Angew. Chem., Int. Ed., 54(6):1799-1802, 2015.

[14] H. Kulla, S. Haferkamp, I. Akhmetova, M. Röllig, C. Maierhofer, K. Rademann, and F Emmerling. In situ investigations of mechanochemical one-pot syntheses. Angew. Chem., Int. Ed., 57(20):5930-5933, 2018.

[15] Manuel Wilke, Lisa Batzdorf, Franziska Fischer, Klaus Rademann, and Franziska Emmerling. Cadmium phenylphosphonates: preparation, characterisation and in situ investigation. RSC Adv., 6(42):3601136019, 2016. 
[16] Manuel Wilke, Ana Guilherme Buzanich, Uwe Reinholz, Klaus Rademann, and Franziska Emmerling. The structure and in situ synthesis investigation of isomorphic mononuclear molecular metal phenylphosphonates. Dalton Trans., 45(23):9460-9467, 2016.

[17] Manuel Wilke, Anke Kabelitz, Annett Zimathies, Klaus Rademann, and Franziska Emmerling. Crystal structure and in situ investigation of a mechanochemical synthesized $3 \mathrm{~d}$ zinc n(phosphonomethyl)glycinate. J. Mater. Sci., 52(20):12013-12020, 2017.

[18] Krunoslav Užarević, Ivan Halasz, and Tomislav Friščić. Real-time and in situ monitoring of mechanochemical reactions: A new playground for all chemists. J. Phys. Chem. Lett., pages 4129-4140, 2015.

[19] S. Lukin, T. Stolar, M. Tireli, V. Blanco Maria, D. Babić, T. Friščić, K. Užarević, and I. Halasz. Tandem in situ monitoring for quantitative assessment of mechanochemical reactions involving structurally unknown phases. Chem. - Eur. J., 23(56):13941-13949, 2017.

[20] I. Halasz, A. Puskaric, S. A. J. Kimber, P. J. Beldon, A. M. Belenguer, F. Adams, V. Honkimaki, R. E. Dinnebier, B. Patel, W. Jones, V. Strukil, and T. Friscic. Real-time in situ powder x-ray diffraction monitoring of mechanochemical synthesis of pharmaceutical cocrystals. Angew. Chem. Int. Ed., 52(44):11538-11541, 2013.

[21] Krunoslav Užarević, Vjekoslav Štrukil, Cristina Mottillo, Patrick A. Julien, Andreas Puškarić, Tomislav Friščć, and Ivan Halasz. Exploring the effect of temperature on a mechanochemical reaction by in situ synchrotron powder x-ray diffraction. Cryst. Growth Des., 16(4):2342-2347, 2016.

[22] Franziska Fischer, Klaus-Jurgen Wenzel, Klaus Rademann, and Franziska Emmerling. Quantitative determination of activation energies in mechanochemical reactions. Phys. Chem. Chem. Phys., 18(33):2332023325, 2016.

[23] Manuel Wilke, Irina Akhmetova, Klaus Rademann, and Franziska Emmerling. Mechanochemical synthesis of cerium(iv)-phosphonates. J. Mater. Sci., 53(19):13733-13741, 2018.

[24] S. L. James, C. J. Adams, C. Bolm, D. Braga, P. Collier, T. Friscic, F. Grepioni, K. D. M. Harris, G. Hyett, W. Jones, A. Krebs, J. Mack, L. Maini, A. G. Orpen, I. P. Parkin, W. C. Shearouse, J. W. Steed, and D. C. Waddell. Mechanochemistry: opportunities for new and cleaner synthesis. Chem. Soc. Rev., 41(1):413-447, 2012.

[25] T. Friščić and L. Fábián. Mechanochemical conversion of a metal oxide into coordination polymers and porous frameworks using liquid-assisted grinding (lag). CrystEngComm, 11(5):743-745, 2009.

[26] E. Boldyreva. Mechanochemistry of inorganic and organic systems: what is similar, what is different? Chem. Soc. Rev., 42(18):7719-7738, 2013.

[27] Adam A. L. Michalchuk, Ivan A. Tumanov, and Elena V. Boldyreva. The effect of ball mass on the mechanochemical transformation of a single-component organic system: anhydrous caffeine. J. Mater. Sci., 53(19):13380-13389, 2018.

[28] Adam A. L. Michalchuk, Ivan A. Tumanov, and Elena V. Boldyreva. Ball size or ball mass - what matters in organic mechanochemical synthesis? CrystEngComm, 21(13):2174-2179, 2019.

[29] F. K. Urakaev and V. V. Boldyrev. Mechanism and kinetics of mechanochemical processes in comminuting devices - 1. theory. Powder Technol., 107(1-2):93-107, 2000.

[30] F. K. Urakaev and V. V. Boldyrev. Mechanism and kinetics of mechanochemical processes in comminuting devices 2. applications of the theory. experiment. Powder Technol., 107(3):197-206, 2000.

[31] F. Delogu, C. Deidda, G. Mulas, L. Schiffini, and G. Cocco. A quantitative approach to mechanochemical processes. J. Mater. Sci., 39(16):5121-5124, 2004. 
[32] O. V. Lapshin, V. V. Boldyrev, and E. V. Boldyreva. Mathematical model of the grinding and mixing of powder binary solids in a high-energy mill. Russ. J. Phys. Chem. A, 93(8):1592-1597, 2019.

[33] A. M. Belenguer, A. A. L. Michalchuk, G. I. Lampronti, and J. K. M. Sanders. Understanding the unexpected effect of frequency on the kinetics of a covalent reaction under ball-milling conditions. Beilstein J. Org. Chem., 15:1226-1235, 2019.

[34] D. Prochowicz, M. Franckevičius, A. M. Cieślak, S. M. Zakeeruddin, M. Grätzel, and J. Lewiński. Mechanosynthesis of the hybrid perovskite ch3nh3pbi3: characterization and the corresponding solar cell efficiency. J. Mater. Chem. A, 3(41):20772-20777, 2015.

[35] Dominik J. Kubicki, Daniel Prochowicz, Albert Hofstetter, Marcin Saski, Pankaj Yadav, Dongqin Bi, Norman Pellet, Janusz Lewiński, Shaik M. Zakeeruddin, Michael Grätzel, and Lyndon Emsley. Formation of stable mixed guanidinium-methylammonium phases with exceptionally long carrier lifetimes for highefficiency lead iodide-based perovskite photovoltaics. J. Am. Chem. Soc., 140(9):3345-3351, 2018.

[36] P. Pal, S. Saha, A. Banik, A. Sarkar, and K. Biswas. All-solid-state mechanochemical synthesis and post-synthetic transformation of inorganic perovskite-type halides. Chem. - Eur. J., 24(8):1811-1815, 2018.

[37] F. Palazon, Y. El Ajjouri, and H. J. Bolink. Making by grinding: Mechanochemistry boosts the development of halide perovskites and other multinary metal halides. Adv. Energy Mater., 2019.

[38] D. Prochowicz, M. Saski, P. Yadav, M. Gratzel, and J. Lewinski. Mechanoperovskites for photovoltaic applications: Preparation, characterization, and device fabrication. Acc. Chem. Res., 52(11):3233-3243, 2019.

[39] Z. H. Hong, D. Tan, R. A. John, Y. K. E. Tay, Y. K. T. Ho, X. Zhao, T. C. Sum, N. Mathews, F. Garcia, and H. S. Soo. Completely solvent-free protocols to access phase-pure, metastable metal halide perovskites and functional photodetectors from the precursor salts. Iscience, 16:312-325, 2019.

[40] Manuel Wilke and Nicola Casati. Insight into the mechanochemical synthesis and structural evolution of hybrid organic-inorganic guanidinium lead(ii) iodides. Chem. - Eur. J., 24(67):17701-17711, 2018.

[41] P. R. Willmott, D. Meister, S. J. Leake, M. Lange, A. Bergamaschi, M. Böge, M. Calvi, C. Cancellieri, N. Casati, A. Cervellino, Q. Chen, C. David, U. Flechsig, F. Gozzo, B. Henrich, S. Jäggi-Spielmann, B. Jakob, I. Kalichava, P. Karvinen, J. Krempasky, A. Lüdeke, R. Lüscher, S. Maag, C. Quitmann, M. L. Reinle-Schmitt, T. Schmidt, B. Schmitt, A. Streun, I. Vartiainen, M. Vitins, X. Wang, and R. Wullschleger. The materials science beamline upgrade at the swiss light source. J. Synchrotron Radiat., 20(Pt 5):667-682, 2013.

[42] C. Prescher and V. B. Prakapenka. DIOPTAS: A program for reduction of two-dimensional x-ray diffraction data and data exploration. High Pressure Res., 35(3):223-230, 2015.

[43] V. Dyadkin, P. Pattison, V. Dmitriev, and D. Chernyshov. A new multipurpose diffractometer PILATUS@SNBL. J. Synchrotron Radiat., 23(3):825-829, 2016.

[44] M. Daub, C. Haber, and H. Hillebrecht. Synthesis, crystal structures, optical properties, and phase transitions of the layered guanidinium-based hybrid perovskites $\left[\mathrm{C}\left(\mathrm{NH}_{2}\right)_{3}\right]_{2} \mathrm{Ml}_{4} ; \mathrm{M}=\mathrm{Sn}, \mathrm{Pb}$. Eur. J. Inorg. Chem., 2017(7):1120-1126, 2017.

[45] S. Elleuch, T. Dammak, Y. Abid, A. Mlayah, and H. Boughzala. Synthesis, structural and optical properties of a novel bilayered organic-inorganic perovskite c5pb2i5. J. Lumin., 130(4):531-535, 2010.

[46] H. M. Powell and H. S. Tasker. The valency angle of bivalent lead: the crystal structure of ammonium, rubidium, and potassium pentabromodiplumbites. Journal of the Chemical Society (Resumed), pages 119-123, 1937. 
[47] A. A. Merkulov, L. I. Isaenko, V. M. Pashkov, V. G. Mazur, A. V. Virovets, and D. Yu Naumov. Crystal structure of kpb2cl5 and kpb2br5. J. Struct. Chem., 46(1):103-108, 2005.

[48] K. H. Wang, L. Wu, L. Li, H. B. Yao, H. S. Qian, and S. H. Yu. Large-scale synthesis of highly luminescent perovskite-related cspb2br5 nanoplatelets and their fast anion exchange. Angew. Chem., Int. Ed., 55(29):8328-8332, 2016.

[49] Olga Nazarenko, Martin Robert Kotyrba, Michael Wörle, Eduardo Cuervo-Reyes, Sergii Yakunin, and Maksym V. Kovalenko. Luminescent and photoconductive layered lead halide perovskite compounds comprising mixtures of cesium and guanidinium cations. Inorg. Chem., 56(19):11552-11564, 2017.

[50] Francesco Delogu, Liliana Schiffini, and Giorgio Cocco. A quantitative description of the amorphisation behaviour by mechanical alloying. Mater. Sci. Forum, 360-362:337-342, 2001.

[51] I. A. Tumanov, A. F. Achkasov, E. V. Boldyreva, and V. V. Boldyrev. Following the products of mechanochemical synthesis step by step. CrystEngComm, 13(7):2213-2216, 2011.

[52] S. S. Razavi-Tousi and J. A. Szpunar. Effect of ball size on steady state of aluminum powder and efficiency of impacts during milling. Powder Technol., 284:149-158, 2015.

[53] P. A. Julien, I. Malvestiti, and T. Friscic. The effect of milling frequency on a mechanochemical organic reaction monitored by in situ raman spectroscopy. Beilstein J. Org. Chem., 13:2160-2168, 2017.

[54] H. Kulla, A. A. L. Michalchuk, and F. Emmerling. Manipulating the dynamics of mechanochemical ternary cocrystal formation. Chem. Commun., 55(66):9793-9796, 2019.

[55] F. Fischer, S. Greiser, D. Pfeifer, C. Jager, K. Rademann, and F. Emmerling. Mechanochemically induced conversion of crystalline benzamide polymorphs by seeding. Angew. Chem., Int. Ed., 55(46):14279-14283, 2016.

[56] S. Haferkamp, A. Paul, A. A. L. Michalchuk, and F. Emmerling. Unexpected polymorphism during a catalyzed mechanochemical knoevenagel condensation. Beilstein J. Org. Chem., 15:1141-1148, 2019.

[57] D. Cincic, I. Brekalo, and B. Kaitner. Solvent-free polymorphism control in a covalent mechanochemical reaction. Cryst. Growth Des., 12(1):44-48, 2012.

[58] M. Zbacnik, I. Nogalo, D. Cincic, and B. Kaitner. Polymorphism control in the mechanochemical and solution-based synthesis of a thermochromic schiff base. CrystEngComm, 17(41):7870-7877, 2015. 


\section{Table of Contents}

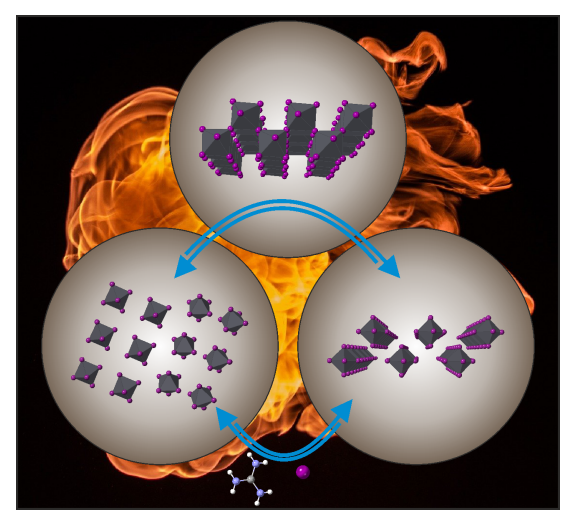

Comprehensive in situ investigations allow the formulation of a mechanism for the mechanochemical formation of two hybrid lead iodides. Via mechanochemistry or temperature the metastable compound can be stabilized. Its formation is strongly correlated with the formation of the second compound, which can be influenced by seeding.

keywords: Mechanochemistry, Solid-state reactions, in situ, X-ray diffraction, Organic-inorganic hybrid composites 